\title{
Carbon emissions intensity reduction target for China's power industry: An efficiency and productivity perspective
}

\author{
Yujiao Xian ${ }^{\text {a,b }}$, Ke Wang ${ }^{\text {a,c,d,* }}$, Xunpeng Shi ${ }^{\text {e,f,g }}$, Chi Zhang ${ }^{\text {h }}$, Yi-Ming Wei ${ }^{\text {a,c,d }}$, Zhimin Huang ${ }^{\text {a,i }}$ \\ ${ }^{a}$ Center for Energy and Environmental Policy Research \& School of Management and Economics, Beijing Institute \\ of Technology, Beijing, China \\ ${ }^{\mathrm{b}}$ Productivity and Efficiency Measurement Laboratory \& Department of Industrial and Systems Engineering, Texas \\ A\&M University, College Station, TX, USA \\ ${ }^{c}$ Sustainable Development Research Institute for Economy and Society of Beijing, Beijing, China \\ ${ }^{\mathrm{d}}$ Beijing Key Lab of Energy Economics and Environmental Management, Beijing, China \\ ${ }^{\mathrm{e}}$ Australia-China Relations Institute, University of Technology Sydney, Ultimo, NSW, Australia \\ ${ }^{\mathrm{f}}$ Center of Hubei Cooperative Innovation for Emissions Trading System, Hubei University of Economics, Wuhan, \\ Hubei, China. \\ ${ }^{\mathrm{g}}$ Energy Studies Institute, National University of Singapore, Singapore \\ ${ }^{\mathrm{h}}$ School of Chemical Science and Engineering, Royal Institute of Technology, Stockholm, Sweden \\ ${ }^{i}$ Robert B. Willumstad School of Business, Adelphi University, Garden City, NY, USA
}

\section{Graphical abstract:}

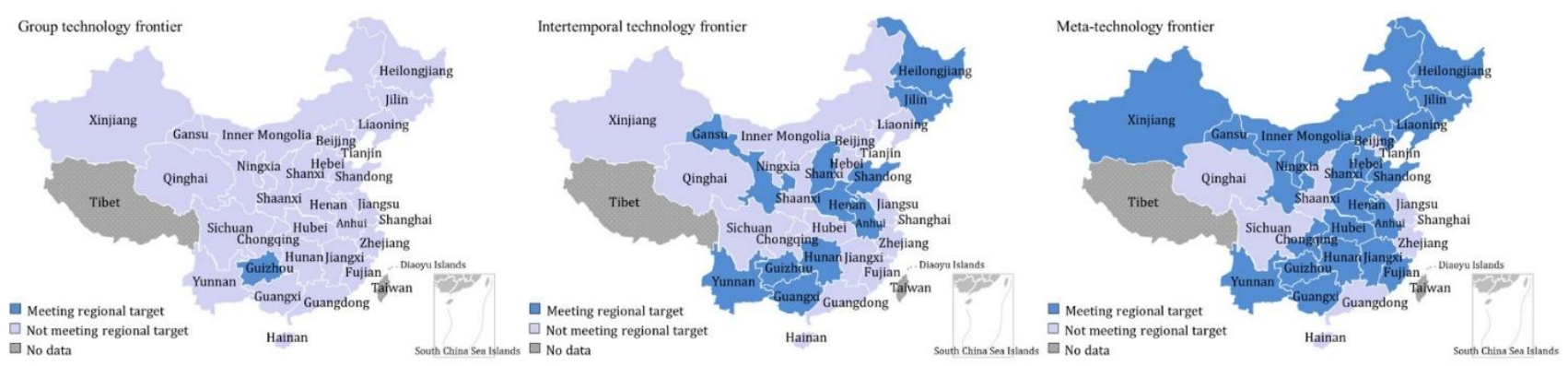

Abstract: This paper proposes a scenario analysis to address whether the national and provincial $\mathrm{CO}_{2}$ emissions intensity reduction target during 2016-2020 would be achievable for China's power industry with the identification of change on carbon productivity. This productivity indicator is further decomposed to investigate contributions of different sources to productivity growth when there exists technological heterogeneity. Evaluation results show that even if all electricity-generating units in each region were able to adopt the best practice, the nationwide $18 \%$ intensity reduction target is not feasible through improving technical efficiency or upgrading technology on electricity generation and carbon abatement in a short or medium term. The existence of regional technological heterogeneity in power generation and associated $\mathrm{CO}_{2}$ emissions reduction processes implies the necessity of more differentiated regulations and policies for emission reduction across China's regions and inter-regional technology transfer. The emerging national emission trading scheme could easy some challenges in formulating emission policy for heterogeneous regions.

Key words: Data Envelopment Analysis (DEA); Endogenous directional distance function (DDF); Meta-technology frontier; Heterogeneity; Technological gap

* Corresponding author. Tel: 86-10-68918651. E-mail address: kewang2083@gmail.com (K. Wang). 


\section{Highlights:}

- Largest $\mathrm{CO}_{2}$ intensity reduction potential in China's provinces is quantified

- Endogenous technique is used to capture largest reduction ratio

- Meta-technology approach is applied to identify technological heterogeneity

- Scenario analysis is utilized to project possible $\mathrm{CO}_{2}$ intensity reduction

- $\mathrm{CO}_{2}$ intensity reduction target is not easy to achieve for China's power industry 


\title{
Graphical abstract:
}
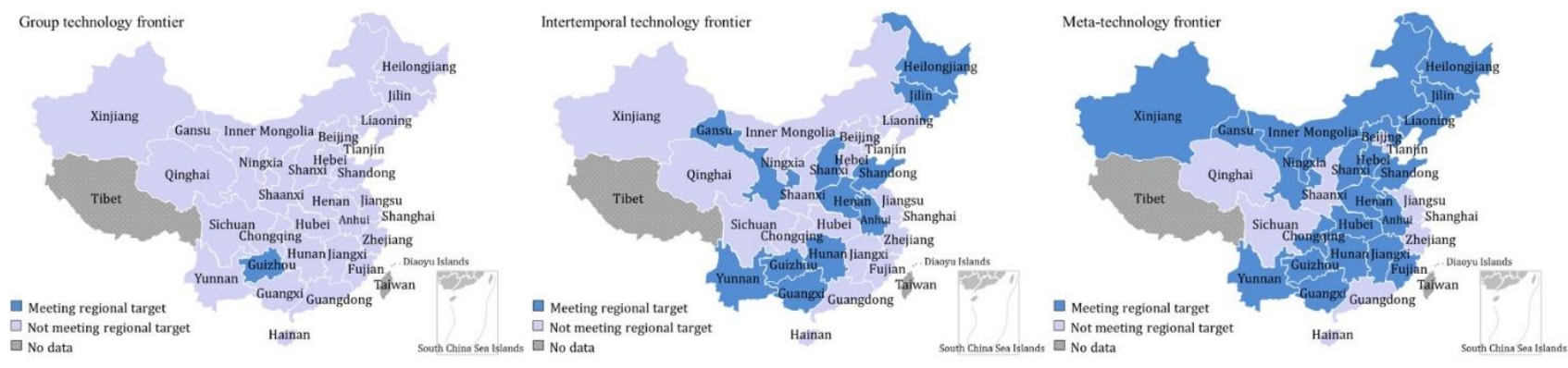

\begin{abstract}
This paper proposes a scenario analysis to address whether the national and provincial $\mathrm{CO}_{2}$ emissions intensity reduction target during 2016-2020 would be achievable for China's power industry with the identification of change on carbon productivity. This productivity indicator is further decomposed to investigate contributions of different sources to productivity growth when
\end{abstract}

* Corresponding author. Tel: 86-10-68918651. E-mail address: kewang2083@gmail.com (K. Wang). 
there exists technological heterogeneity. Evaluation results show that even if all electricity-generating units in each region were able to adopt the best practice, the nationwide $18 \%$ intensity reduction target is not feasible through improving technical efficiency or upgrading technology on electricity generation and carbon abatement in a short or medium term. The existence of regional technological heterogeneity in power generation and associated $\mathrm{CO}_{2}$ emissions reduction processes implies the necessity of more differentiated regulations and policies for emission reduction across China's regions and inter-regional technology transfer. The emerging national emission trading scheme could easy some challenges in formulating emission policy for heterogeneous regions.

Key words: Data Envelopment Analysis (DEA); Endogenous directional distance function (DDF); Meta-technology frontier; Heterogeneity; Technological gap

\section{Introduction}

Global warming and climate change has increasingly become a public concern and a serious challenge in energy policy-making for all governments. The temperature of global surface increased $0.74 \pm 0.18{ }^{\circ} \mathrm{C}$ during 20 th century (IPCC, 2013). In the United Nations Framework Convention on Climate Change (UNFCCC) Conference of the Parties (COP) in Paris of 2015, there is a globally accepted target $\left(2^{\circ} \mathrm{C}\right)$ and ambition target $\left(1.5^{\circ} \mathrm{C}\right)$ for limiting global temperature rise.

The increase of fossil fuel consumption, which is the main driving force of global warming and climate change, has led to the global socio-economic development and large-scale $\mathrm{CO}_{2}$ emissions (Chen et al., 2018). As the world's largest emitter of $\mathrm{CO}_{2}$, China had announced a series of agreements and targets on climate change mitigation. For example, on the Copenhagen climate change summit in 2009, China announced that it would reduce its $\mathrm{CO}_{2}$ emissions intensity of GDP (i.e., $\mathrm{CO}_{2}$ emissions per unit of GDP) by $40-45$ percent by 2020 relative to the 2005 -level (Paltsev et 
al., 2012). Furthermore, in the COP 2015in Paris, the Chinese government had made three major commitments in its Intended Nationally Determined Contribution (INDC) regarding $\mathrm{CO}_{2}$ emissions. The first is to peak its $\mathrm{CO}_{2}$ emissions no later than 2030. The second is to reduce its $\mathrm{CO}_{2}$ emissions intensity of GDP by $60-65$ percent by 2030 relative to its 2005 -level. The third is to increase the share of non-fossil energy in the total primary energy supply to 20 percent by 2030 (Bjorn, 2016). To meet these targets, China implemented a series policies and regulations in each Five-Year Plan (FYP) period. FYP, which is formulated by Chinese government, guides the national economy and social development and environmental protection. Table 1 presents some nationwide targets in $11^{\text {th }}, 12^{\text {th }}$ and $13^{\text {th }}$ FYP. According the nationwide $18 \%$ reduction target, each province in China also implemented its regional $\mathrm{CO}_{2}$ emissions intensity (i.e., $\mathrm{CO}_{2}$ emissions per unit of total output value) reduction target of $13^{\text {th }}$ FYP.

\section{Table 1 Nationwide targets on energy conservation and carbon control}

\begin{tabular}{ccc}
\hline Periods & \multicolumn{2}{c}{ Reduction targets } \\
& $\begin{array}{c}\text { Energy intensity } \\
\mathrm{CO}_{2} \text { emissions intensity }\end{array}$ & $\begin{array}{c}\mathrm{SCC}^{2} \text { (SCC, 2007; SCC, 2011a) } \\
(\mathrm{SCC}, 2011 \mathrm{~b} ; \text { SCC, 2016) }\end{array}$ \\
\hline $11^{\text {th }}$ FYP (2006-2010) & $20 \%$ & - \\
$12^{\text {th }}$ FYP (2011-2015) & $16 \%$ & $17 \%$ \\
$13^{\text {th }}$ FYP (2016-2020) & - & $18 \%$ \\
\hline
\end{tabular}

Note: Energy intensity is final energy consumption per unit of GDP; $\mathrm{CO}_{2}$ emissions intensity is $\mathrm{CO}_{2}$ emissions per unit of GDP.

Achieving the $\mathrm{CO}_{2}$ emissions intensity reduction target in China's electricity generation sector plays a crucial role in the national efforts to control $\mathrm{CO}_{2}$ emissions and other air pollutants (Wang et al., 2016b; Wang et al., 2018b). According to the International Energy Agency (IEA, 2011), China's power sector, which is dominated by the consumption of fossil fuels and nonrenewable energies, accounts for about $50 \%$ of China's total $\mathrm{CO}_{2}$ emission in 2010 . Whether the $\mathrm{CO}_{2}$ emission targets for the electricity sector is achievable is an issue that is important to the Chinese policy makers and the global community that is fighting with climate change. For the Chinese policy makers, another question, which is also significant for formulating the policies that promote the energy and 
environmental efficiency, is how to further reduce $\mathrm{CO}_{2}$ emissions (Hampf and Rødseth, 2015).

The present paper has two aims. The first aim is to evaluate the feasibility of the nationwide $(18 \%)$ and provincial $\mathrm{CO}_{2}$ emissions intensity reduction target for China's power industry in $13^{\text {th }}$ FYP given its existing technologies of generation and emission control. The second aim is to identify the ways in which the reduction targets can be reached from the perspective of productivity change. Thus, this study evaluates the carbon productivity of China's power industry in the $12^{\text {th }}$ FYP period and identify the driving forces for their improvement.

An evaluation of carbon efficiency and productivity of power industry sector for China's 30 provinces is offered using an endogenous directional distance function (DDF) proposed by Färe et al. (2013) to identify the largest efficiency improvement potential and the meta-technology frontier approach to solve the problem of the technological heterogeneity among provinces. Understanding the technological frontier is significant for identifying the feasibility of $\mathrm{CO}_{2}$ emissions intensity reduction target. Improving the carbon efficiency and productivity is an important way to achieve the $\mathrm{CO}_{2}$ emissions intensity reduction target. Meanwhile, the factorial decomposition of productivity change in the past trends could help researchers to identify the drivers in objective variable, i.e., the reduction on $\mathrm{CO}_{2}$ emissions intensity.

Existing studies on DDF and productivity change decomposition have faced several challenges. First, in most applications of DDF, the directional vector is selected by the researchers. This selection is arbitrary and does not guarantee capturing the largest efficiency improvement potential (Adler and Volta, 2016; Wang et al., 2016a). Second, most of the existing studies applying meta-frontier technique only analyzed the group differences from the spatial dimension perspective (Oh, 2010; Hančlová and Melecký, 2016; Barros and Wanke, 2017; Feng et al., 2018). In other words, most researchers only employed the cross-sectional data to do an analysis. Hence, the other dimension perspective, that is the temporal perspective, should be considered into the meta-frontier technique to do some further analysis. Third, the existing scenario analysis and decomposition analysis only 
focused on the decomposition of productivity change into efficiency change and technical change (i.e., best practice gap change) (Du et al. 2014; Lee et al., 2015; Lin and Zhao, 2016). Therefore, more drivers need be explored in the productivity evaluation via scenario analysis.

This study makes the following contributions to the existing literature at the theoretical and the application level. First, the endogenous DDF approach provides a more reasonable evaluation of the $\mathrm{CO}_{2}$ emissions intensity reduction target in China's power industry through identifying the largest efficiency improvement potential. Second, the meta-technology technique takes into account the technological heterogeneity of different power industry sectors across China's regions, providing a more proper estimation of the driving forces of carbon productivity growth in China's power industry. Third, this study takes both the spatial dimension and the temporal dimension into consideration via scenario analysis, presenting a more comprehensive investigation on the productivity change from the perspective of technical efficiency change (TEC), best practice gap change (BPC), and technological gap change $(T G C)$. Fourth, this is the first study to examine the feasibility of emission target for China's power generation sector in $13^{\text {th }}$ FYP and investigate additional policy option to achieve the target.

This reminder of this paper is organized as follows: Section 2 is the literature review. Section 3 introduces the methodology including the production and environmental technologies and endogenous efficiency estimation method, the meta-technology frontier approach, and the Luenberger productivity indicator and its decomposition. Section 4 presents the empirical study of the examination of the feasibility of $\mathrm{CO}_{2}$ emissions intensity reduction target and the identification of productivity change in China's power industry. Section 5 concludes the study.

\section{Method}

In this study, to measure the carbon efficiency and productivity, the nonparametric DDF 
approach based on the DEA technique is employed to estimate the technologies. An endogenous efficiency measure is proposed for Luenberger productivity indicator of meta-technology and its decomposition. A brief explanation of the technical issues will be presented in the next three sub-sections and the scenario design will be explained in section 2.4 .

\subsection{Production and environmental technologies and endogenous efficiency estimation}

By considering a production process of $j=1,2, \ldots, n$ observed power industry sectors at provincial level, each province comprises a vector of input $\boldsymbol{x}_{j}=\left(x_{1 j}, x_{2 j}, \ldots, x_{i j}, \ldots, x_{m j}\right) \in \boldsymbol{R}_{+}^{m}$, a vector of intended (or good) outputs $\boldsymbol{y}_{j}=\left(y_{1 j}, y_{2 j}, \ldots, y_{r j}, \ldots, y_{s j}\right) \in \boldsymbol{R}_{+}^{s}$, and a vector of unintended (or bad) outputs $\boldsymbol{u}_{j}=\left(u_{1 j}, u_{2 j}, \ldots, u_{f j}, \ldots, u_{h j}\right) \in \boldsymbol{R}_{+}^{h}$. The production possibility set $\boldsymbol{T}$ of this production process is a combination of all technically feasible input-output, and is denoted by:

$$
\boldsymbol{T}=\left\{(\boldsymbol{x}, \boldsymbol{y}, \boldsymbol{u}) \in \boldsymbol{R}_{+}^{m+s+h}: \boldsymbol{x} \text { can produce }(\boldsymbol{y}, \boldsymbol{u})\right\}
$$

The production possibility set $\mathrm{T}$ satisfies the following axioms (Färe and Grosskopf, 2004) on technology: i) Nonempty and closed; ii) Convexity; iii) Inputs are free disposable: If $(\boldsymbol{x}, \boldsymbol{y}, \boldsymbol{u}) \in \boldsymbol{T}$ and $\boldsymbol{x}^{\prime} \geq \boldsymbol{x}$, then $\left(\boldsymbol{x}^{\prime}, \boldsymbol{y}, \boldsymbol{u}\right) \in \boldsymbol{T} ;$ iv) Intended outputs are free disposable: If $(\boldsymbol{x}, \boldsymbol{y}, \boldsymbol{u}) \in \boldsymbol{T}$ and $\boldsymbol{y}^{\prime} \leq \boldsymbol{y}$, then $\left.\left(\boldsymbol{x}, \boldsymbol{y}^{\prime}, \boldsymbol{u}\right) \in \boldsymbol{T} ; \mathrm{v}\right)$ Unintended outputs and intended outputs are jointly weakly disposable: If $(\boldsymbol{x}, \boldsymbol{y}, \boldsymbol{u}) \in \boldsymbol{T}$ and $0 \leq \rho \leq 1$, then $(\boldsymbol{x}, \rho \boldsymbol{y}, \rho \boldsymbol{u}) \in \boldsymbol{T}$; vi) Unintended outputs and intended outputs are null-joint: If $(\boldsymbol{x}, \boldsymbol{y}, \boldsymbol{u}) \in \boldsymbol{T}$ and $\mathrm{u}=\mathbf{0}$, then $\boldsymbol{y}=\mathbf{0}$.

The weak disposability axiom indicates that the contraction of unintended outputs is costly since the intended outputs must be decreased correspondingly. More explicitly, inputs would be reallocated between the production of intended outputs and the regulation of unintended outputs. In addition, the null-jointness assumption suggests that there would be no intended outputs without unintended outputs. 
On the basis of these axioms this sub-section then describes the preparation of the DDF. Under the background of evaluating environmental efficiency and productivity, Chambers et al. (1996a) and Chung et al. (1997) introduced the DDF. Since the seminal work of Chambers et al. (1996a), the DDF is a widely used approach to analyze the energy and environmental issues (Picazo-Tadeo et al., 2012; Wang et al., 2013; Halkos et al., 2016). It can help to model the pollution technologies, i.e., expand desirable outputs and control pollution or energy inputs simultaneously.

DDF estimation can be operationalized via both parametric estimation approach and the non-parametric estimation approach. The parametric estimation approach, which is usually employed to estimate the shadow prices of pollution, is based on a regression model such as Stochastic Frontier Analysis (SFA) model. Hence, it needs a specified form of production function for efficiency estimation. The applications of this approach can be found in Vardanyan and Noh (2006), Färe et al. (2012) and Fetanat and Shafipour (2017). The non-parametric estimation approach is based on a mathematical programming model such as data envelopment analysis (DEA) model, and thus, it does not need to specify production function. DEA is an effective efficiency technique in the multiple-input and multiple-output setting without specifying any functional form and pre-assigned weights. This approach has been widely utilized in energy and environmental efficiency measurement, such as Park et al. (2008), Wang et al. (2016c), Wang et al. (2016d), Barros et al. (2017), Chen et al. (2017), Wanke et al. (2017) and Díaz-Villavicencio et al. (2017).

This formulation of DDF, which expands intended (or good) outputs and contracts unintended (or bad) outputs simultaneously, is a better strategy than traditional distance function proposed by Shephard (1970) on efficiency estimation. Its corresponding definition in an output-oriented model is denotes as:

$$
\overrightarrow{\boldsymbol{D}}(\boldsymbol{x}, \boldsymbol{y}, \boldsymbol{u} ; \overrightarrow{\boldsymbol{g}})=\max \left\{\beta:\left(\boldsymbol{x}, \boldsymbol{y}+\beta \overrightarrow{\boldsymbol{g}}_{\boldsymbol{y}}, \boldsymbol{u}-\beta \overrightarrow{\boldsymbol{g}}_{u}\right) \in \boldsymbol{T}\right\}
$$


In which $\beta(\geq 0)$ is the inefficiency score of the evaluated province and $\overrightarrow{\boldsymbol{g}}=\left(\overrightarrow{\boldsymbol{g}}_{\boldsymbol{y}},-\overrightarrow{\boldsymbol{g}}_{\boldsymbol{u}}\right)$ is a directional vector. The province under evaluated is efficient if $\beta=0$, and is inefficient if $\beta>0$. In addition, $\beta g_{y_{r}} / y_{r}$ is the inefficiency score of intended output $y_{r}$, and $\beta g_{u_{f}} / u_{f}$ is the inefficiency score of unintended output $u_{f}$.

However, for the application of DDF based on DEA technique, the directional vectors are usually arbitrarily selected by the researchers in advance (Wang et al., 2017; Wang et al., 2018a). Hence, there would be no trade-offs between intended and unintended outputs in this arbitrary selection process. Another weakness is that it would underestimate the inefficiency scores when there are some non-zero slacks on outputs (Fukuyama and Weber, 2009; Barros and Wanke, 2017). Furthermore, when using the weak disposability axiom mentioned above, there would be a downward-sloping segment of unintended outputs where the frontier has a negative slope (Picazo-Tadeo and Prior, 2009; Chen and Delmas, 2012). In this situation, some inefficient points located on this segment would be misclassification as efficient along with the arbitrary directions. To overcome these difficulties, Färe et al. (2013) and Hampf and Krüger (2014) proposed an endogenous technique to select the directional vectors, i.e., maximizing the inefficiency score of the evaluated province over the directions. The associated DEA model for evaluated province $j_{0}$ under variable return to scale (VRS) can be presented as follows: 


$$
\begin{aligned}
& \max _{\beta, \lambda_{j}, \alpha_{r_{0}}, \partial_{f_{0}}} \sum_{r=1}^{s} \frac{\beta}{\beta \alpha_{r j_{0}}+1} \\
& \text { s.t. } \quad x_{i j_{0}} \geq \sum_{j=1}^{n} x_{i j}\left(\lambda_{1 j}+\lambda_{2 j}\right), i=1,2, \ldots, m \\
& y_{r_{0}}+\beta \alpha_{r_{j}} y_{r_{j}} \leq \sum_{j=1}^{n} y_{r j} \lambda_{l j}, r=1,2, \ldots, s \\
& u_{f_{j_{0}}}-\beta \delta_{f_{f_{0}}} u_{f_{f_{0}}}=\sum_{j=1}^{n} u_{f j} \lambda_{l j}, f=1,2, \ldots, h \\
& \sum_{r=1}^{s} \alpha_{r j_{0}}+\sum_{f=1}^{f} \delta_{f_{j_{0}}}=1 \\
& \sum_{j=l}^{n}\left(\lambda_{l j}+\lambda_{2 j}\right)=1 \\
& \beta, \lambda_{l j}, \lambda_{2 j}, \alpha_{r_{0}}, \delta_{f_{0}} \geq 0, j=1,2, \ldots, n, r=1,2, \ldots, s, f=1,2, \ldots, h .
\end{aligned}
$$

In our model, the objective function is to maximize the reduction percentage of $\mathrm{CO}_{2}$ emissions intensity. $\lambda_{1 j}$ and $\lambda_{2 j}$ indicates the intensity variable, whereas $\alpha$ and $\delta$ represent the different weights for intended and unintended outputs, respectively. The non-negative constraints on weight variables intimate that only the directions $\overrightarrow{\boldsymbol{g}}=\left(\overrightarrow{\boldsymbol{g}}_{\boldsymbol{y}},-\overrightarrow{\boldsymbol{g}}_{u}\right)=(\alpha \circ \boldsymbol{y},-\delta \circ \boldsymbol{u})$ that would not reduce intended outputs or expand unintended outputs can been chosen, where "॰" indicates the Hadamard product for two vectors.

\subsection{Meta-technology}

Since the measurement of carbon efficiency and productivity makes the effort of carbon control accountable, the productivity growth is considered a key indicator in assessing carbon performance change. However, a conventional productivity index is not capable of distinguishing the heterogeneity from differentiated technologies (Battese et al., 2002; Heshmati et al., 2012; Sueyoshi et al., 2018). In recent studies, many researches focus on the technological heterogeneity from a theoretical perspective (Moreira and Bravo-Ureta, 2010; Fallahfini et al., 2012; Makni et al., 2015). In other words, these studies assume that provinces process different level of production technology due to the differences in socioeconomic condition, geographical location, generation fuel mix and industrialization level. 
To solve this problem, some researchers employed the meta-frontier technique that is capable in distinguishing production technologies by classifying them into different groups, such as Wanke and Barros (2016) and Azad et al. (2017). The concept of meta-frontier, which is introduced by Hayami (1969), is to ensure that all heterogeneous units are assessed based on a common and identical frontier. In other words, the aim of introducing meta-frontier is to provide a homogeneous frontier for heterogeneous units (Battese et al. 2004). The meta-frontier can be interpreted as a wrapper of all possible boundaries that could possibly result from the heterogeneity between units (O'Donnell et al., 2008).

Following the meta-frontier technique, a set of technologies from both the spatial dimension and the temporal dimension are modelled as follow. Supposing our sample can be divided into $H$ groups with different group technology $\boldsymbol{T}_{h}(h=1,2, \ldots, H)$, and the units in each group have similar technology in each period $t(t=1,2, \ldots, T)$. Hereafter, the intertemporal technology of group $h$ is defined as $\boldsymbol{T}_{h}^{I}=\operatorname{Conv}\left(\boldsymbol{T}_{h}^{1} \cup \boldsymbol{T}_{h}^{2} \cup \ldots \cup \boldsymbol{T}_{h}^{T}\right),(h=1,2, \ldots, H)$. This production technology contains all observations of group $h$ in the entire study period. Moreover, the meta-technology of all groups is defined as $\boldsymbol{T}^{M}=\operatorname{Conv}\left(\boldsymbol{T}_{1}^{I} \cup \boldsymbol{T}_{2}^{I} \cup \ldots \cup \boldsymbol{T}_{H}^{I}\right)$. This production technology covers all observations and envelops all the intertemporal technologies.

Fig. 1 shows a meta-technology model with one intended output and one unintended output. Supposing there are two groups and their intertemporal technology frontiers $(I T F)$ are labeled with $1_{1}$ and $\mathrm{l}_{2}$, while the meta-technology frontier $(M T F)$ encompasses these two frontiers and is labeled with $\mathrm{m}_{1}$. In addition, assuming there are three periods for each group. For group 1, the group technology frontier $(G T F)$ for time $t_{1}, t_{2}$ and $t_{3}$ is respectively labeled with $g_{1}, g_{2}$, and $g_{3}$, whereas the ITF encompassed these three frontiers and is labeled with $l_{1}$. 


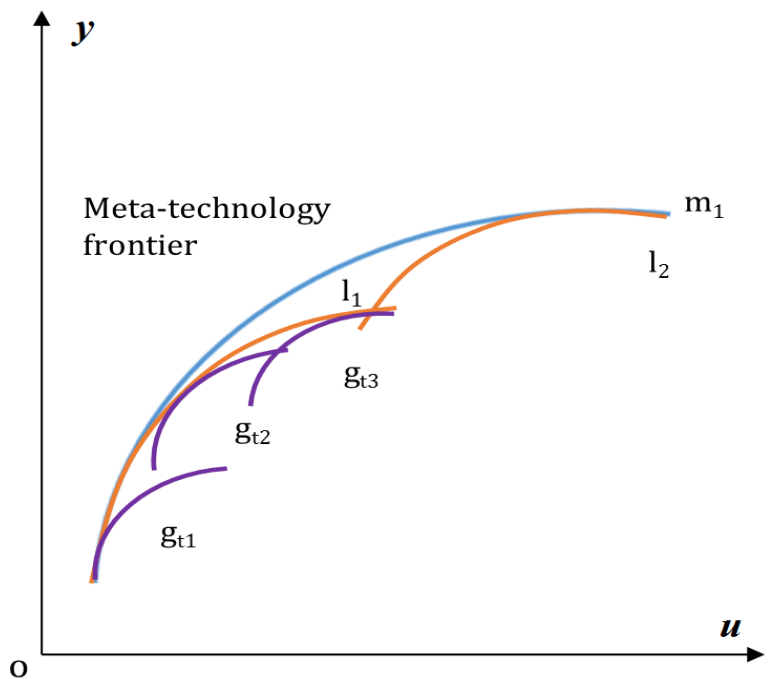

Fig. 1 GTF, ITF and MTF

Thus, applying Eq. (2) to the $G T F, I T F$ and $M T F$, respectively:

$$
\begin{gathered}
\overrightarrow{\boldsymbol{D}}_{h}(\boldsymbol{x}, \boldsymbol{y}, \boldsymbol{u} ; \overrightarrow{\boldsymbol{g}})=\beta_{h}=\max \left\{\beta:\left(\boldsymbol{x}, \boldsymbol{y}+\beta \overrightarrow{\boldsymbol{g}}_{\boldsymbol{y}}, \boldsymbol{u}-\beta \overrightarrow{\boldsymbol{g}}_{u}\right) \in \boldsymbol{T}_{h}\right\}, h=1,2, \ldots, H \\
\overrightarrow{\boldsymbol{D}}_{h}^{I}(\boldsymbol{x}, \boldsymbol{y}, \boldsymbol{u} ; \overrightarrow{\boldsymbol{g}})=\beta_{h}^{I}=\max \left\{\beta:\left(\boldsymbol{x}, \boldsymbol{y}+\beta \overrightarrow{\boldsymbol{g}}_{\boldsymbol{y}}, \boldsymbol{u}-\beta \overrightarrow{\boldsymbol{g}}_{u}\right) \in \boldsymbol{T}_{h}^{I}\right\}, h=1,2, \ldots, H . \\
\overrightarrow{\boldsymbol{D}}^{M}(\boldsymbol{x}, \boldsymbol{y}, \boldsymbol{u} ; \overrightarrow{\boldsymbol{g}})=\beta^{M}=\max \left\{\beta:\left(\boldsymbol{x}, \boldsymbol{y}+\beta \overrightarrow{\boldsymbol{g}}_{\boldsymbol{y}}, \boldsymbol{u}-\beta \overrightarrow{\boldsymbol{g}}_{u}\right) \in \boldsymbol{T}^{M}\right\} .
\end{gathered}
$$

where $\overrightarrow{\boldsymbol{D}}_{h}(\boldsymbol{x}, \boldsymbol{y}, \boldsymbol{u} ; \overrightarrow{\boldsymbol{g}})$ measures the distance between the evaluated unit and the GTF of group $h$, and $\overrightarrow{\boldsymbol{D}}_{h}^{I}(\boldsymbol{x}, \boldsymbol{y}, \boldsymbol{u} ; \overrightarrow{\boldsymbol{g}})$ measures the distance between the evaluated unit and the ITF of group $h$, whereas $\overrightarrow{\boldsymbol{D}}^{M}(\boldsymbol{x}, \boldsymbol{y}, \boldsymbol{u} ; \overrightarrow{\boldsymbol{g}})$ measures the distance between the evaluated unit and the MTF.

\subsection{Luenberger productivity indicator and its decomposition}

Employing the concept of DDF, the Luenberger productivity indicator of meta-technology (LPIM) and intertemporal technology (LPII) of group $h$ can be respectively defined as follows:

$$
\begin{aligned}
\operatorname{LPIM}\left(\boldsymbol{x}^{t}, \boldsymbol{y}^{t}, \boldsymbol{u}^{t} ; \boldsymbol{x}^{t+1}, \boldsymbol{y}^{t+1}, \boldsymbol{u}^{t+1}\right) & =\overrightarrow{\boldsymbol{D}}^{M}\left(\boldsymbol{x}^{t}, \boldsymbol{y}^{t}, \boldsymbol{u}^{t}\right)-\overrightarrow{\boldsymbol{D}}^{M}\left(\boldsymbol{x}^{t+1}, \boldsymbol{y}^{t+1}, \boldsymbol{u}^{t+1}\right) \\
& =\beta^{M}\left(\boldsymbol{x}^{t}, \boldsymbol{y}^{t}, \boldsymbol{u}^{t}\right)-\beta^{M}\left(\boldsymbol{x}^{t+1}, \boldsymbol{y}^{t+1}, \boldsymbol{u}^{t+1}\right)
\end{aligned}
$$




$$
\begin{aligned}
\operatorname{LPII}_{h}\left(\boldsymbol{x}^{t}, \boldsymbol{y}^{t}, \boldsymbol{u}^{t} ; \boldsymbol{x}^{t+1}, \boldsymbol{y}^{t+1}, \boldsymbol{u}^{t+1}\right) & =\overrightarrow{\boldsymbol{D}}_{h}^{I}\left(\boldsymbol{x}^{t}, \boldsymbol{y}^{t}, \boldsymbol{u}^{t}\right)-\overrightarrow{\boldsymbol{D}}_{h}^{I}\left(\boldsymbol{x}^{t+1}, \boldsymbol{y}^{t+1}, \boldsymbol{u}^{t+1}\right) \\
& =\beta_{h}^{I}\left(\boldsymbol{x}^{t}, \boldsymbol{y}^{t}, \boldsymbol{u}^{t}\right)-\beta_{h}^{I}\left(\boldsymbol{x}^{t+1}, \boldsymbol{y}^{t+1}, \boldsymbol{u}^{t+1}\right) \\
\operatorname{LPIG}_{h}\left(\boldsymbol{x}^{t}, \boldsymbol{y}^{t}, \boldsymbol{u}^{t} ; \boldsymbol{x}^{t+1}, \boldsymbol{y}^{t+1}, \boldsymbol{u}^{t+1}\right) & =\overrightarrow{\boldsymbol{D}}_{h}^{G}\left(\boldsymbol{x}^{t}, \boldsymbol{y}^{t}, \boldsymbol{u}^{t}\right)-\overrightarrow{\boldsymbol{D}}_{h}^{G}\left(\boldsymbol{x}^{t+1}, \boldsymbol{y}^{t+1}, \boldsymbol{u}^{t+1}\right) \\
& =\beta_{h}^{G}\left(\boldsymbol{x}^{t}, \boldsymbol{y}^{t}, \boldsymbol{u}^{t}\right)-\beta_{h}^{G}\left(\boldsymbol{x}^{t+1}, \boldsymbol{y}^{t+1}, \boldsymbol{u}^{t+1}\right)
\end{aligned}
$$

where $L P I G_{h}$ and $L P I I_{h}$ measure the efficiency (or productivity) change within the groups, and $L P I M$ measures the efficiency (or productivity) chenge between the groups.

To identify the sources of productivity change under meta-technology, as mentioned above, most studies only analyze the group differences in the spatial dimension and focus on the decomposition into efficiency change and technical change (i.e., best practice gap change).

From the perspective from both the spatial dimension and the temporal dimension, this study further investigates the productivity change from the contribution of technical efficiency change (TEC), best practice gap change $(B P C)$ and technological gap change $(T G C)$. Similar to the decomposition of Malmquiste-Luenberger index in Munisamy and Arabi (2015), $L P I I_{h}$ can be also decomposed into technical efficiency change and best practice gap change, whereas we can decompose LPIM into technical efficiency change, best practice gap change and technology gap change, as follows:

$$
\begin{aligned}
\operatorname{LPII}_{h} & \left(\boldsymbol{x}^{t}, \boldsymbol{y}^{t}, \boldsymbol{u}^{t} ; \boldsymbol{x}^{t+1}, \boldsymbol{y}^{t+1}, \boldsymbol{u}^{t+1}\right) \\
= & \beta_{h}^{I}\left(\boldsymbol{x}^{t}, \boldsymbol{y}^{t}, \boldsymbol{u}^{t}\right)-\beta_{h}^{I}\left(\boldsymbol{x}^{t+1}, \boldsymbol{y}^{t+1}, \boldsymbol{u}^{t+1}\right) \\
= & \underbrace{\left[\beta_{h}^{G}\left(\boldsymbol{x}^{t}, \boldsymbol{y}^{t}, \boldsymbol{u}^{t}\right)-\beta_{h}^{G}\left(\boldsymbol{x}^{t+1}, \boldsymbol{y}^{t+1}, \boldsymbol{u}^{t+1}\right)\right]}_{T E C_{h}\left(\boldsymbol{x}^{t}, \boldsymbol{y}^{t}, \boldsymbol{u}^{\prime} ; \boldsymbol{x}^{t+1}, \boldsymbol{y}^{t+1}, \boldsymbol{u}^{t+1}\right)}+ \\
& \underbrace{\left[\left(\beta_{h}^{I}\left(\boldsymbol{x}^{t}, \boldsymbol{y}^{t}, \boldsymbol{u}^{t}\right)-\beta_{h}^{G}\left(\boldsymbol{x}^{t}, \boldsymbol{y}^{t}, \boldsymbol{u}^{t}\right)\right)-\left(\beta_{h}^{I}\left(\boldsymbol{x}^{t+1}, \boldsymbol{y}^{t+1}, \boldsymbol{u}^{t+1}\right)-\beta_{h}^{G}\left(\boldsymbol{x}^{t+1}, \boldsymbol{y}^{t+1}, \boldsymbol{u}^{t+1}\right)\right)\right]}_{B P C_{h}\left(\boldsymbol{x}^{t}, \boldsymbol{y}^{t}, \boldsymbol{u}^{t} ; \boldsymbol{x}^{t+1}, \boldsymbol{y}^{t+1}, \boldsymbol{u}^{t+1}\right)}
\end{aligned}
$$


In Equations (10) and (11), TEC measures the change on technical efficiency, identifying the movement towards or against the $G T F$. It reveals the catch-up effort of the evaluated units. $B P C$ measures the change in best practice gap $(B P G)$, capturing the gap between the ITF and each period $G T F$. It reveals the technical change of the evaluated units over time. $T G C$ measures the change in technology gap $(T G)$, representing the gap between the $M T F$ and the ITF for each group. It reveals the technological leadership change of the evaluated units, which can be achieved through the generation fuel mix adjustment in this study. Specifically, TEC reflects the technical efficiency change through expanding intended outputs and/or reducing pollutants in the short term given the inputs unchanged. $B P C$ reflects the technical progress or regress in the medium term within one group that shows no heterogeneity in electricity generation technology. $T G C$ reflects the technology progress or regress in the long term between groups with technological heterogeneity.

Note that the positive or negative values of $T E C, B P C$ and $T G C$ respectively indicate technical efficiency improvement or deterioration, technical progress or regress, and technological leadership progress or regress, while zero values on $T E C, B P C$ and $T G C$ indicate no changes.

It should be noticed that the strategy for reducing carbon intensity in this study is from the perspective of optimizing energy consumption structure, improving technical efficiency, and promoting production technology for electricity generation, but without considering the direct reduction of energy consumption. The thermal power generation in China had significantly increased 
in the $12^{\text {th }} \mathrm{FYP}$ and will continue increase in the $13^{\text {th }} \mathrm{FYP}$ in accordance with the growth trends and the national development policies (NDRC, 2016), and thus, the total emissions are likely to increase continuously. For convenience, all variables, parameters and indicators are presented in Table 2.

Table 2 Summary of variables, parameters and indicators

\begin{tabular}{|c|c|c|}
\hline \multirow{3}{*}{ Parameters } & Inputs & $\boldsymbol{x}_{j}=\left(x_{1 j}, x_{2 j}, \ldots, x_{i j}, \ldots, x_{m j}\right) \in \boldsymbol{R}_{+}^{m}$ \\
\hline & Intended outputs & $\boldsymbol{y}_{j}=\left(y_{1 j}, y_{2 j}, \ldots, y_{r j}, \ldots, y_{s j}\right) \in \boldsymbol{R}_{+}^{s}$ \\
\hline & Unintended outputs & $\boldsymbol{u}_{j}=\left(u_{1 j}, u_{2 j}, \ldots, u_{f j}, \ldots, u_{h j}\right) \in \boldsymbol{R}_{+}^{h}$ \\
\hline \multirow{6}{*}{ Variables } & Inefficiency score under $h_{\text {th }}$ group technology frontier & $\overrightarrow{\boldsymbol{D}}_{h}(\boldsymbol{x}, \boldsymbol{y}, \boldsymbol{u} ; \overrightarrow{\boldsymbol{g}})=\beta_{h}$ \\
\hline & $\begin{array}{l}\text { Inefficiency score under } h_{\text {th }} \text { intertemporal group technology } \\
\text { frontier }\end{array}$ & $\overrightarrow{\boldsymbol{D}}_{h}^{I}(\boldsymbol{x}, \boldsymbol{y}, \boldsymbol{u} ; \overrightarrow{\boldsymbol{g}})=\beta_{h}^{I}$ \\
\hline & Inefficiency score under meta technology frontier & $\overrightarrow{\boldsymbol{D}}^{M}(\boldsymbol{x}, \boldsymbol{y}, \boldsymbol{u} ; \overrightarrow{\boldsymbol{g}})=\beta^{M}$ \\
\hline & Intensity variable & $\lambda_{I j}, \lambda_{2 j}$ \\
\hline & The weight of inefficiency for intended outputs & $\alpha$ \\
\hline & The weight of inefficiency for unintended outputs & $\delta$ \\
\hline \multirow{9}{*}{ Indicators } & Group technology frontier & GTF \\
\hline & Intertemporal technology frontier & ITF \\
\hline & Meta-technology frontier & MTF \\
\hline & $\begin{array}{l}\text { Productivity change within } h_{\text {th }} \text { group under group } \\
\text { technology frontier }\end{array}$ & $L P I G_{h}$ \\
\hline & $\begin{array}{l}\text { Productivity change within } h_{\text {th }} \text { group under intertemporal } \\
\text { group technology frontier }\end{array}$ & $L P I I_{h}$ \\
\hline & Productivity change between groups & LPIM \\
\hline & Technical efficiency change & $T E C$ \\
\hline & Best practice gap change & $B P C$ \\
\hline & Technology gap change & $T G C$ \\
\hline
\end{tabular}

\subsection{Scenario design}

Scenario analysis is a useful tool to project future possible reduction of $\mathrm{CO}_{2}$ emissions intensity according to various time span conditions. However, the main objective of scenario analysis method is to reveal how much the current $\mathrm{CO}_{2}$ emissions intensity of the power industry sector would be reduced and then find the feasibility of $\mathrm{CO}_{2}$ emissions intensity reduction target.

To project the future possible reduction of $\mathrm{CO}_{2}$ emissions intensity in China's power industry sector, we set four scenarios to provide a comparison of results under different time span conditions in the $12^{\text {th }}$ FYP. The possible reduction of $\mathrm{CO}_{2}$ emissions intensity for the four scenarios was 
calibrated by the actual reduction during 2014-2015, 2013-2015, 2012-2015 and the entire $12^{\text {th }}$ FYP, respectively. The increasing reduction in longer time span due to more technologies and economic structure changes overtime suggesting that Scenario 4 will have more reduction potential that the rest scenarios and Scenario 1 has the least reduction potential.

Based on these four scenarios, we could have an in-depth insight into the possible reduction of $\mathrm{CO}_{2}$ emissions intensity under different time span conditions.

\section{Dataset}

This study calculates the largest reduction percentage on $\mathrm{CO}_{2}$ emissions intensity using a database containing the power industry sectors of 30 provinces of China that were in operation during the $12^{\text {th }}$ FYP period. Tibet, Hong Kong, Macau and Taiwan are not included in our sample because their data are missing and they are not involved in the energy saving and emission reduction policies of China. The motivations to employ the date of the $12^{\text {th }}$ FYP period are twofold. First, the data of the $12^{\text {th }}$ FYP is the basis of the $13^{\text {th }}$ FYP, and thus, the formulation and realization of reduction target in the $13^{\text {th }}$ FYP both have a direct relationship with the data of the $12^{\text {th }}$ FYP. Second, this paper discusses the possibility of the target realization of carbon intensity reduction from the perspective of potential. The existing intensity reduction potential is obtained from the existing data of the $12^{\text {th }} \mathrm{FYP}$ and has a significant impact on the possibility of the target realization.

Our technologies consist of three inputs (employee, fuel consumption and installed capacity) which are used to generate one intended output (gross electricity generation) and one unintended output $\left(\mathrm{CO}_{2}\right.$ emissions) for each provincial power industry sector. The reduction of emissions or emission intensity at provincial level is usually realized through the strategies of optimizing fuel consumption structure and increasing utilization efficiency of fuel through improving technical efficiency over time. The inclusion of the above three operational inputs and one emission output 
simultaneously helps to appropriately capture the productivity change and its driving forces, i.e., technical efficiency change, best practice gap change, and technological gap change, which are in accordance with these strategies, and thus the identified emission reduction potentials and derived policy implications could be specifically targeted to the adjustments on these operational inputs.

The data on employee are collected from the China Industry Economy Statistical Yearbook (2012-2016), while the data on fuel consumption, installed capacity and gross electricity generation are collected from the Wind database*. Moreover, the data on $\mathrm{CO}_{2}$ emissions is calculated based on the fuel consumption that is decomposed into coal, oil and natural gas. In specific, the fuel consumption related $\mathrm{CO}_{2}$ emissions is calculated by using the carbon emission factors for the combustion of coal, oil and natural gas obtained from IPCC Guidelines for National Greenhouse Gas Inventories and the conversion factors from physical unit to coal equivalent (ce) collected from China's energy statistical yearbooks. Table 3 reports the summary statistics of our dataset.

Table 3 Summary statistics of inputs and outputs of China's 30 provincial power industry sectors

\begin{tabular}{|c|c|c|c|c|c|c|}
\hline Inputs and output & Year & 2011 & 2012 & 2013 & 2014 & 2015 \\
\hline \multirow{4}{*}{$\begin{array}{l}\text { Employee } \\
\text { (thousand persons) }\end{array}$} & Mean & 89.92 & 94.57 & 95.21 & 94.53 & 116.35 \\
\hline & St. Dev. & 50.09 & 53.71 & 55.10 & 49.53 & 70.20 \\
\hline & Minimum & 9.20 & 11.75 & 12.30 & 12.20 & 19.10 \\
\hline & Maximum & 212.35 & 211.20 & 211.30 & 212.30 & 280.70 \\
\hline \multirow{4}{*}{$\begin{array}{l}\text { Fuel consumption } \\
\text { (million ton of ce) }\end{array}$} & Mean & 47.49 & 49.22 & 52.94 & 54.62 & 57.13 \\
\hline & St. Dev. & 30.19 & 30.52 & 32.80 & 33.89 & 33.77 \\
\hline & Minimum & 4.90 & 5.38 & 6.18 & 6.51 & 6.88 \\
\hline & Maximum & 113.42 & 117.03 & 126.83 & 127.36 & 140.01 \\
\hline \multirow{4}{*}{$\begin{array}{l}\text { Installed capacity } \\
(\text { million } \mathrm{kW})\end{array}$} & Mean & 35.16 & 38.13 & 41.54 & 45.29 & 51.73 \\
\hline & St. Dev. & 20.39 & 21.76 & 23.56 & 25.43 & 25.90 \\
\hline & Minimum & 4.25 & 5.02 & 5.10 & 5.14 & 6.35 \\
\hline & Maximum & 76.31 & 77.96 & 83.53 & 92.14 & 99.35 \\
\hline \multirow{4}{*}{$\begin{array}{l}\text { Electricity } \\
\text { (billion kWh) }\end{array}$} & Mean & 153.38 & 160.56 & 174.76 & 182.06 & 190.74 \\
\hline & St. Dev. & 98.97 & 100.81 & 109.14 & 112.74 & 113.35 \\
\hline & Minimum & 16.91 & 19.20 & 21.52 & 22.94 & 24.47 \\
\hline & Maximum & 375.56 & 392.84 & 428.89 & 434.67 & 465.14 \\
\hline \multirow{4}{*}{$\begin{array}{l}\mathrm{CO}_{2} \\
\text { (million tons) }\end{array}$} & Mean & 130.81 & 130.17 & 133.71 & 129.91 & 113.23 \\
\hline & St. Dev. & 100.78 & 104.04 & 100.54 & 100.34 & 94.36 \\
\hline & Minimum & 11.15 & 12.06 & 13.19 & 10.83 & 11.46 \\
\hline & Maximum & 402.88 & 417.67 & 382.12 & 405.41 & 401.55 \\
\hline
\end{tabular}

\footnotetext{
http://www.wind.com.cn/
} 
When calculating the carbon intensity reduction potentials and analyzing the carbon productivity change, the effect of carry-over activities between two consecutive terms has already been accounted in this study, namely, the selected inputs and outputs variables are all work in the current period. On the one hand, the fuel consumption represents the energy consumption during the current period, whereas the gross electricity generation represents the electricity generation quantity in the current period. Moreover, since the provincial average working hours have no significant difference among employees in the power industry, the number of employee can be considered as a proxy of the labor input in the current period. On the other hand, although carbon emissions have a long-term impact on society and environment, this study focus on the feasibility and reasonability of the carbon intensity reduction target which is accounted in each single year. Hence, we use the annual carbon emissions for analysis.

Since increasing renewable energy consumption and energy transformation are both important energy strategies for controlling $\mathrm{CO}_{2}$ emissions (Qi and $\mathrm{Li}, 2017$ ), the evaluation in this study is conducted on four groups: low-fossil-fuel area, medium-fossil-fuel area, high-fossil-fuel area and fossil-fuel-dominated area. These groups are comprehensively characterized by the level of economic development, the level of regional carbon emission reduction target, the number of electricity generation and the share of fossil fuel consumption in the total energy consumption for electricity generation. The final grouping of these four areas respectively account $0-65 \%, 65 \%-85 \%$, $86 \%-94 \%$ and $94 \%-100 \%$ fossil fuel consumption in the total energy consumption for electricity generation. The main reason for the group classification in this study is the technological heterogeneity. On the one hand, different energy types have different emission factor, and thus, the structure of energy consumption in generating electricity would directly affect the quantity of $\mathrm{CO}_{2}$ emissions. On the other hand, since each energy type has its corresponding power generator and technological capacity, this group classification could distinguish different power generators with different power generation technology. Fig. 2 shows the production technology of electricity 
generation and $\mathrm{CO}_{2}$ emissions for these four groups. It can be seen that there are indeed significant differences in the production technology among groups during $12^{\text {th }}$ FYP period, and thus, our grouping is meaningful for analysis. Fig. 3 presents the geographical distribution of these four groups.
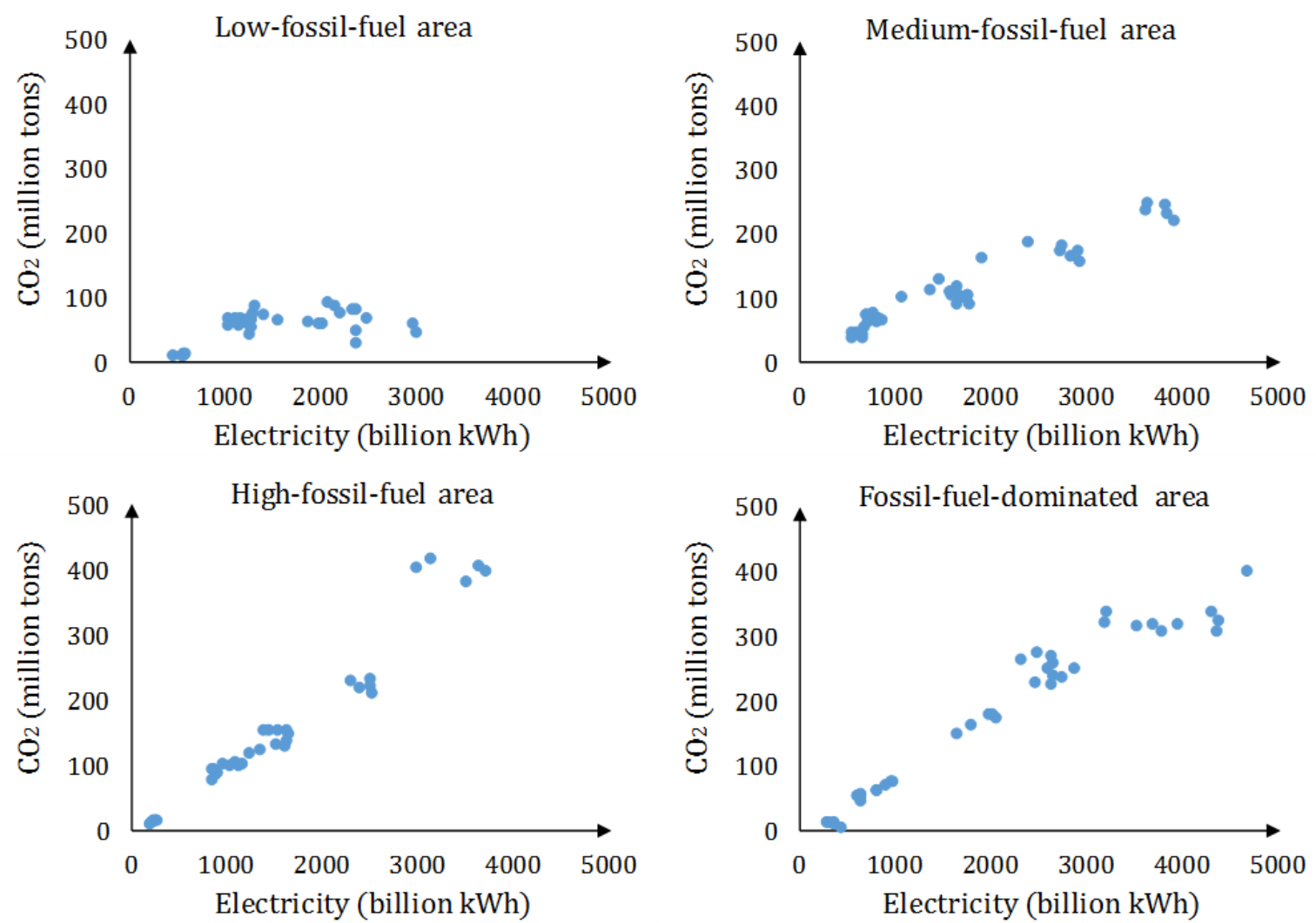

Fig. 2 Different production technologies among areas during $12^{\text {th }}$ Five-Year period 
Low fossil-fuel area

: Medium-fossil-fuel area

$\equiv$ High-fossil-fuel area

III Fossil-fuel-dominated area

No data

Fig. 3 The geographical distribution of four groups with different shares of fossil fuel

\section{Results}

This section first evaluates the feasibility of $\mathrm{CO}_{2}$ emissions intensity reduction target in the $13^{\text {th }}$ FYP under four scenarios, and then presents the results of productivity change and its driving forces.

To evaluate the feasibility of $\mathrm{CO}_{2}$ emissions intensity reduction target, the largest reduction on $\mathrm{CO}_{2}$ emissions intensity (i.e., the optimal reduction ratio) is first estimated for each provincial power sector, namely, the largest reduction on $\mathrm{CO}_{2}$ emissions intensity could be achieved if the electricity generating units adopt best practices, using the endogenous efficiency measurement introduced in Section 2.2. These estimated largest reduction percentages on $\mathrm{CO}_{2}$ emissions intensity are then compared with the $\mathrm{CO}_{2}$ emissions intensity reduction target.

Because there is not a special target for China's power industry sector, we here use three kinds of targets (i.e., the $\mathrm{CO}_{2}$ emissions intensity target at national level, at provincial level and at firm 
level) as a baseline target for the power industry ${ }^{*}$. At the national level, the government's target of $18 \%$ $\mathrm{CO}_{2}$ emissions intensity reduction during the $13^{\text {th }} \mathrm{FYP}$ period is adopted as the baseline target. At provincial level, each province had also announced to reduce its corresponding $\mathrm{CO}_{2}$ emissions intensity of total output value (i.e., $\mathrm{CO}_{2}$ emissions per unit of total output value) during the $13^{\text {th }}$ FYP period, which is set as the baseline target. At the firm level, the government target for the large power generation units, that is, a cap of $\mathrm{CO}_{2}$ emissions per unit of electricity supply at $550 \mathrm{~g} \mathrm{CO} / \mathrm{kWh}$ during the $13^{\text {th }}$ FYP is adopted as the baseline target.

\subsection{The feasibility of $\mathrm{CO}_{2}$ emissions intensity target at national level}

Under group technology, intertemporal technology and meta-technology, Fig. 4 depicts the largest reduction on $\mathrm{CO}_{2}$ emissions intensity at the national level. The nationwide $18 \%$ reduction target is compared with the largest reduction percentage on $\mathrm{CO}_{2}$ emissions intensity for the whole country and for each group. As shown in Fig. 5, our results indicate that, firstly, through technical efficiency improvement in the short term (i.e., expanding electricity generation and reducing $\mathrm{CO}_{2}$ emissions given the current inputs), the optimal reduction ratio for the whole country could be reduced by $2.09 \%, 1.92 \%, 2 \%$ and $2.45 \%$ on average under the four scenarios, respectively. Ratios of the low-fossil-fuel area, medium-fossil-fuel area, high-fossil-fuel area and fossil-fuel-dominated area could range from $0 \%$ to $0.71 \%, 1.17 \%$ to $2.89 \%, 1.31 \%$ to $1.83 \%$ and $3.52 \%$ to $5.42 \%$ on average, respectively. All of these reduction potentials are quite lower than the $18 \%$ reduction target.

Secondly, through both the technical efficiency improvement and the technical progress on electricity generation and carbon abatement in the medium term within each group, an average

* Since the provincial average electricity price is regulated and almost steady in China, the gross electricity generation can be considered as an equivalent of the gross industrial output in power industry. Therefore, it is reasonable to compare the reduction target of $\mathrm{CO}_{2}$ emissions per unit of GDP (or total output value) with the largest reduction percentage of $\mathrm{CO}_{2}$ emissions per unit of electricity generation in China's power industry sector. 
$7.01 \%, 9.03 \%, 12.27 \%$ and $13.52 \%$ national emission reduction under the four scenarios can be achieved according to the intertemporal technology. Specifically, the largest reduction ratios of the low-fossil-fuel area, medium-fossil-fuel area, high-fossil-fuel area and fossil-fuel-dominated area range from $7.87 \%$ to $26.57 \%, 3.95 \%$ to $8.92 \%, 3.40 \%$ to $7.04 \%$ and $10.17 \%$ to $12.38 \%$ on average respectively. These reduction potentials are much close to the $18 \%$ national reduction target. The largest reduction ratios of the low-fossil-fuel area could be $26.03 \%$ and $26.57 \%$ in scenario 3 and 4 , and thus achieve the nationwide $18 \%$ target.

Thirdly, through both the technical efficiency improvement and the technical progress on electricity generation and carbon abatement within group, as well as the technological transfer between groups that can be gradually realized in the long term, the national reduction ratio could at least $40.02 \%$ on average according to the meta-technology. In addition, under this circumstance, the largest reduction ratios of all four areas $(32.82 \%-42.01 \%, 53.62 \%-54.89 \%, 43.07 \%-44.65 \%$ and 24.53\%-31.22\%) under these four scenarios can be also far higher than the $18 \%$ reduction target.

The above evaluation reveals that, even if all units were able to adopt their best practice in the short term or in the medium term, the $18 \% \mathrm{CO}_{2}$ emissions intensity reduction target of the $13^{\text {th }}$ FYP could not be achieved through improving the technical efficiency and upgrading the technology on electricity generation and carbon abatement. However, this target could be achieved in the medium and long term, with substantial technical progress in each area associated with technological transfer among provinces, and effective generation fuel mix adjustment for electricity generation and carbon abatement. 


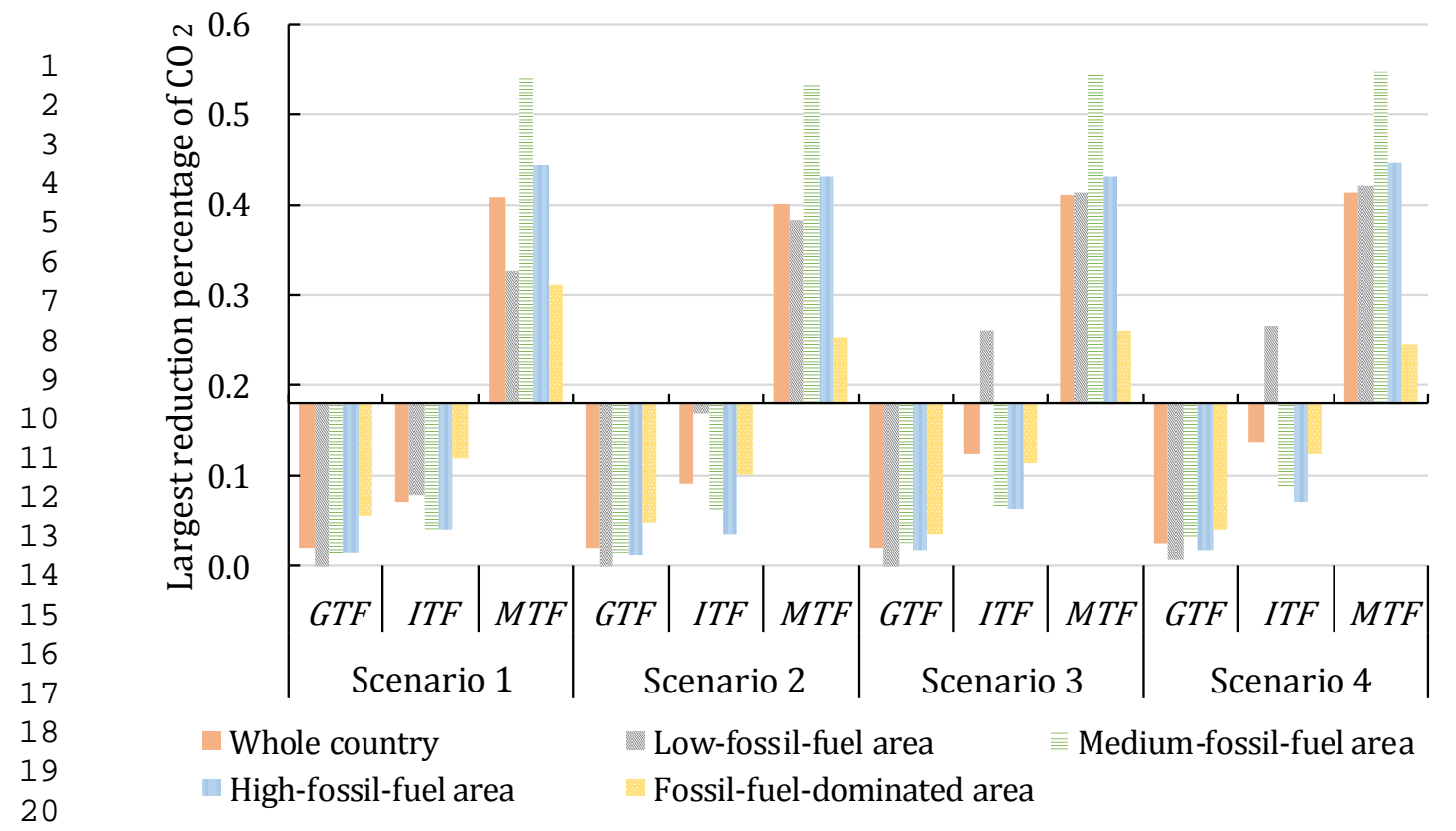

Fig. 4 Largest reduction percentage on $\mathrm{CO}_{2}$ emissions intensity for whole country and each group

\subsection{The feasibility of $\mathrm{CO}_{2}$ emissions intensity target at provincial level}

The provincial reduction targets are compared with the largest reduction potential on $\mathrm{CO}_{2}$ emissions intensity at the provincial level. Fig. 5 shows the $\mathrm{CO}_{2}$ emissions reduction percentages from adopting best practice in 30 provinces under four scenarios. It can be seen that the largest reduction percentage on $\mathrm{CO}_{2}$ emissions intensity is various among China's provinces and among different technologies, but the results among four scenarios are similar. Specifically, under all three technologies, the feasible emissions reduction percentage of eight provinces (Sichuan, Qinghai, Zhejiang, Guangdong, Hainan, Shaanxi, Beijing and Jiangsu) is far less than the $\mathrm{CO}_{2}$ emissions intensity reduction target of $13^{\text {th }}$ FYP in all four scenarios. Shanghai and Tianjin can only achieve their corresponding targets under meta-technology during 2014-2015 scenario. One of the most vital reasons may be that due to their advanced development level, these provinces have relatively higher technical efficiencies and thus smaller emission reduction potential. Moreover, in all scenarios, the $\mathrm{CO}_{2}$ emissions reduction ratios of nine provinces (Hubei, Fujian, Xinjiang, Jiangxi, Chongqing, Hebei, Inner Mongolia, Liaoning, and Ningxia) are higher than their provincial $\mathrm{CO}_{2}$ emissions intensity reduction target but only under meta-technology. That means, in order to achieve the $\mathrm{CO}_{2}$ 
emissions intensity reduction target, these provinces will have to adjust their fuel mix in the medium and long term.

In addition, the $\mathrm{CO}_{2}$ emissions reduction potential of ten provinces (Yunnan, Guangxi, Gansu, Hunan, Jilin, Heilongjiang, Shandong, Anhui, Shanxi and Henan) can be higher than their provincial $\mathrm{CO}_{2}$ emissions intensity reduction target under both intertemporal technology and meta-technology. The possible emissions reduction potential of Guizhou could be higher than its $12 \%$ regional target under all three technologies in scenario 3 and 4. In other words, these eleven provinces can achieve the $\mathrm{CO}_{2}$ emissions intensity reduction target of $13^{\text {th }} \mathrm{FYP}$ through the technical progress on electricity generation and carbon abatement within group and/or the technological transfer between groups. These results give an important suggestion that, since the maximizing reduction potential on $\mathrm{CO}_{2}$ emissions intensity are various among regions, the regulations and policies implemented for $\mathrm{CO}_{2}$ emissions control in power industry should be different across China's regions. The results also suggest that inter-provincial transfer of technologies is necessary as some province can only achieve their targets through catching up with the $M T F$. 

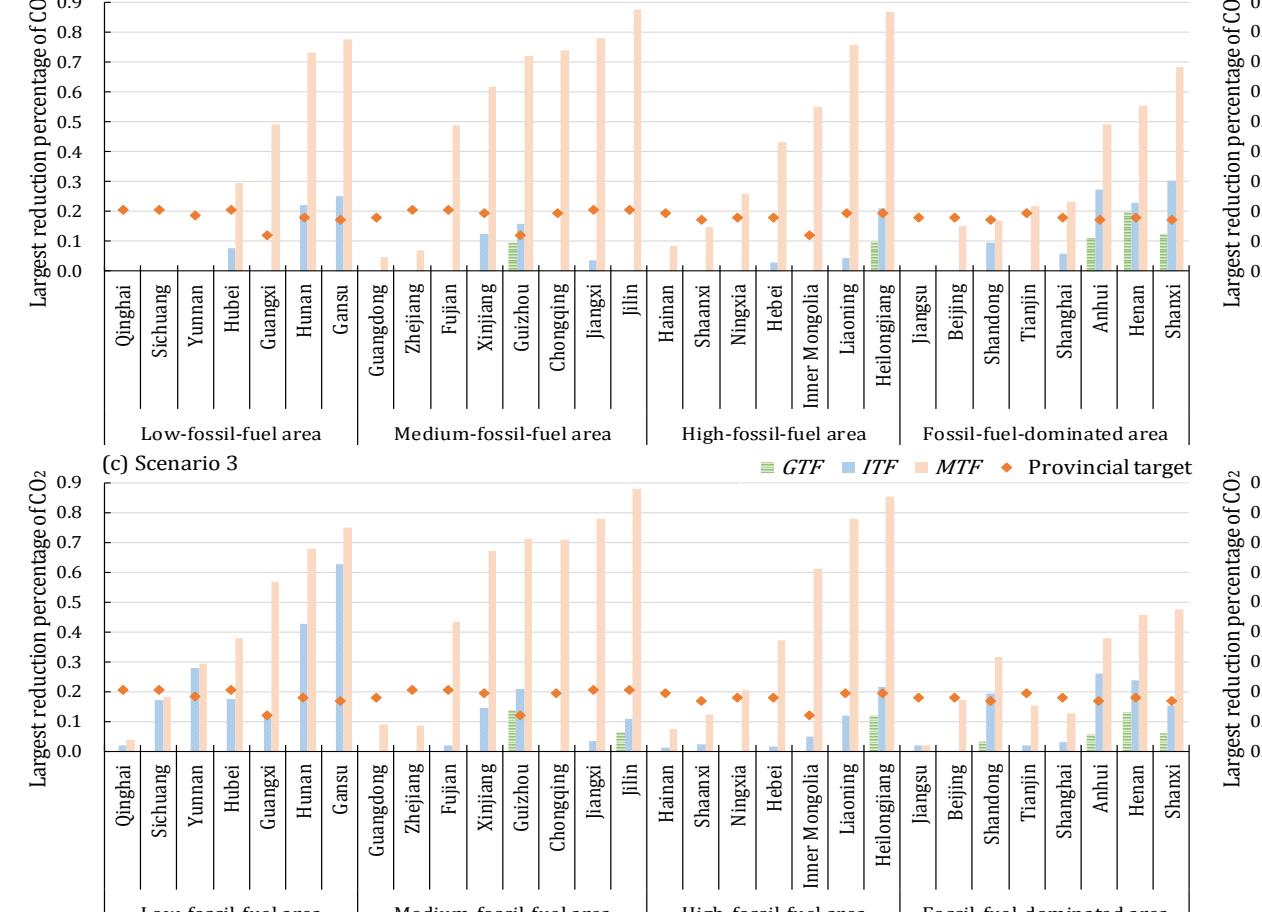

Fig. 5 Largest reduction percentage on $\mathrm{CO}_{2}$ emissions intensity for each province
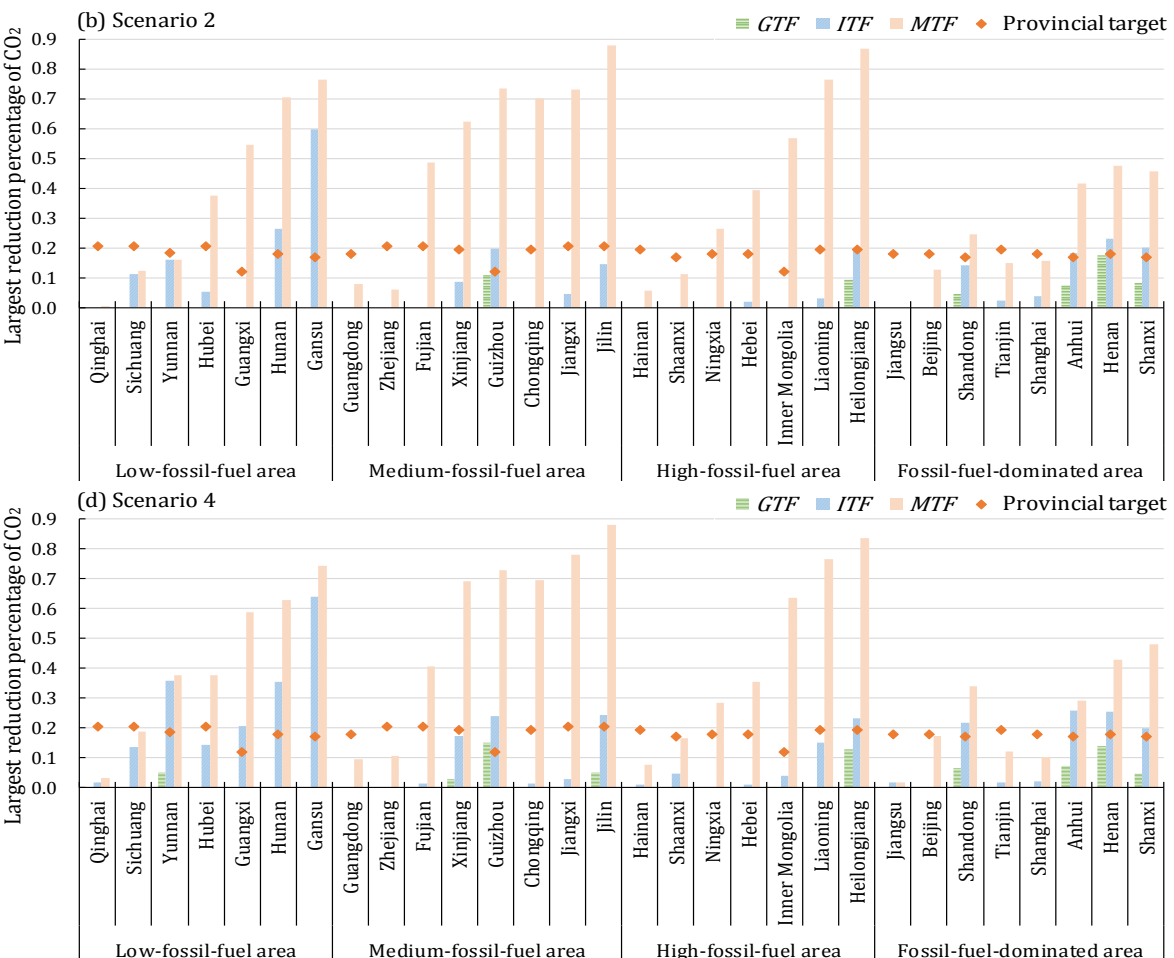


\subsection{The feasibility of $\mathrm{CO}_{2}$ emissions intensity target at firm level}

In this sub-section, we compare the results of $\mathrm{CO}_{2}$ emissions intensity of electricity generation (i.e., optimal $\mathrm{CO}_{2}$ emissions per unit of electricity generation) for each province's power sector with the $550 \mathrm{~g} \mathrm{CO}_{2} / \mathrm{kWh}$ target.

Table 4 presents the results of optimal $\mathrm{CO}_{2}$ emissions intensity of electricity generation using the endogenous efficiency measurement and three technology frontiers introduced in Section 2.2. For the whole country, the target of capping $\mathrm{CO}_{2}$ emissions intensity of electricity generation at $550 \mathrm{~g}$ $\mathrm{CO}_{2} / \mathrm{kWh}$ can only be achieved under $M T F$. It means that the feasibility of $\mathrm{CO}_{2}$ emissions intensity target for China's power industry sector not only need the technical progress on electricity generation and carbon abatement within group and the technological transfer between groups, but also need to adjust fuel mix for power generation units.

The $\mathrm{CO}_{2}$ emissions intensity of electricity generation of low-fossil-fuel area performs best and is smaller than $470 \mathrm{~g} \mathrm{CO} / \mathrm{kWh}$ under all technologies. For medium-fossil-fuel area and high-fossil-fuel area, the $\mathrm{CO}_{2}$ emissions intensity of electricity generation can only achieve the $550 \mathrm{~g}$ $\mathrm{CO}_{2} / \mathrm{kWh}$ target through the joint efforts of technical progress, technology transfer and the adjustment of fuel mix. In addition, it is worth noting that the fossil-fuel-dominated area is hard to achieve the $550 \mathrm{~g} \mathrm{CO}_{2} / \mathrm{kWh}$ target.

In addition, the introduction of renewable energy and the adjustment of fuel mix for power generation units are the necessary means to control China's carbon emissions.

Table 4 Results of $\mathrm{CO}_{2}$ emissions intensity of electricity generation $\left(\mathrm{g} \mathrm{CO}_{2} / \mathrm{kWh}\right)$

\begin{tabular}{ccccccccccccc}
\hline & \multicolumn{3}{c}{ Scenario 1} & \multicolumn{3}{c}{ Scenario } & \multicolumn{3}{c}{ Scenario 3} & \multicolumn{3}{c}{ Scenario 4 } \\
& GTF & ITF & MTF & GTF & ITF & MTF & GTF & ITF & MTF & GTF & ITF & MTF \\
\hline Total & 666 & 629 & 367 & 688 & 640 & 394 & 706 & 637 & 399 & 722 & 642 & 407 \\
Low-fossil-fuel area & 347 & 307 & 186 & 374 & 290 & 188 & 389 & 260 & 188 & 409 & 275 & 466 \\
Medium-fossil-fuel area & 695 & 673 & 292 & 715 & 676 & 308 & 717 & 684 & 304 & 731 & 676 & 442 \\
High-fossil-fuel area & 895 & 870 & 482 & 909 & 888 & 499 & 928 & 881 & 510 & 950 & 895 & 391
\end{tabular}




\subsection{Driving forces of the productivity change}

To design a reasonable target of $\mathrm{CO}_{2}$ emissions reduction for each region, it is necessary to analyze the driving forces for carbon productivity change in China's power industry. Hence, the next step of this study is to evaluate the change on carbon performance of China's power industry sector in $12^{\text {th }}$ FYP period and further discuss the sources of carbon productivity growth through utilizing the productivity indicators introduced in Section 2.3.

Fig. 6 shows the technology gap of each group, which represents the extent to which the ITF of individual group deviates from the $M T F$. In this figure, since all trends of technology gap of scenario 1, 2 and 3 are the part of scenario 4, and thus, only the results of scenario 4 are discussed here.

From 2011 onwards, low-fossil-fuel area and fossil-fuel-dominated area have represented a premier technology and have formed the $M T F$. It implies that the regions that have relatively high shares of renewable energy consumption in total energy consumption or mainly rely on thermal power for electricity generation, have performed significantly better in electricity generation than the regions with mixed energy consumption during our study period. 
(a) Scenario 1
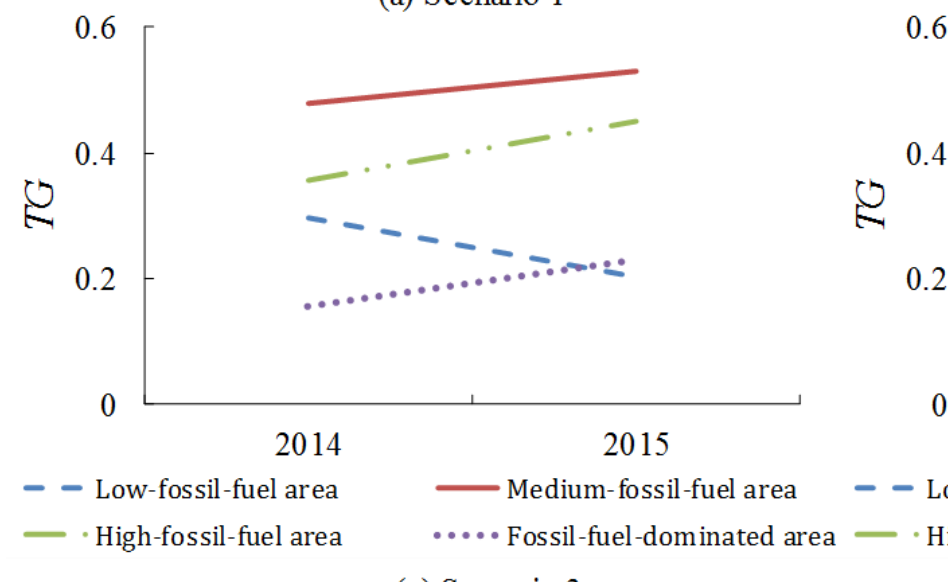

(c) Scenario 3

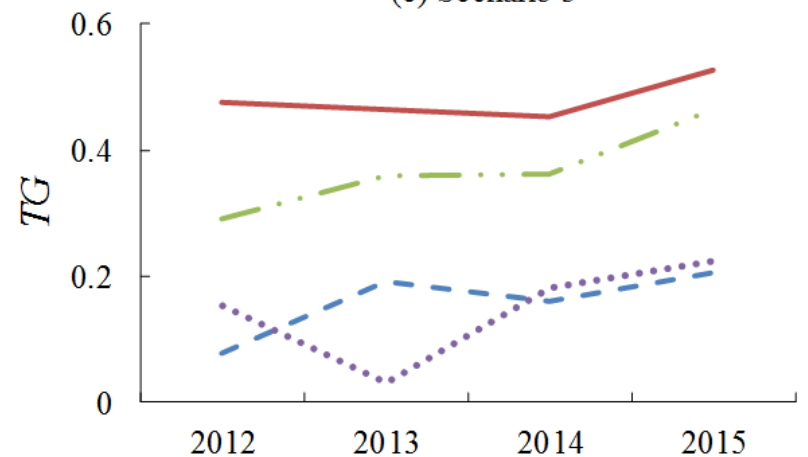

- - Low-fossil-fuel area

— Medium-fossil-fuel area

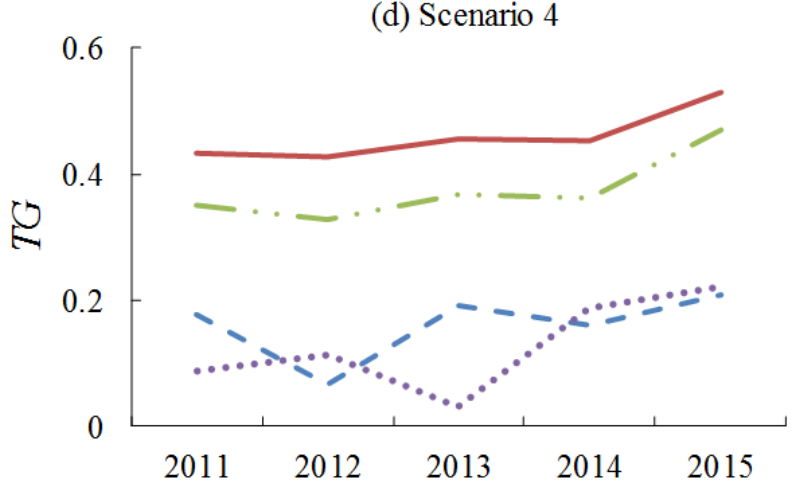

- High-fossil-fuel area

.... Fossil-fuel-dominated area

- - Low-fossil-fuel area

— Medium-fossil-fuel area

Fig. 6 Technology gap for all four groups

The Luenberger productivity indicator of meta-technology for four groups during 2011-2015 scenario is presented in Fig. 7, measuring the productivity growth in the long term between groups through both improving the technical efficiency and upgrading the technology, as well as through the technological transmission on electricity generation and carbon abatement. As can be seen from this figure, the LPIM of medium-fossil-fuel area and high-fossil-fuel area are around zero and the LPIM of high-fossil-fuel area experiences a little drop in 2014-2015. Althougy there are more fluctuation in low-fossil-fuel area and fossil-fuel-dominated area during the study period, this component is also around zero in general. These above observations can be verified by the $T$-test listed in Table 5 . This result reveals that, since the technical efficiency, the technology and the technological transfer on electricity generation and carbon abatement show no significant improvement, there is almost no productivity growth among all areas. 


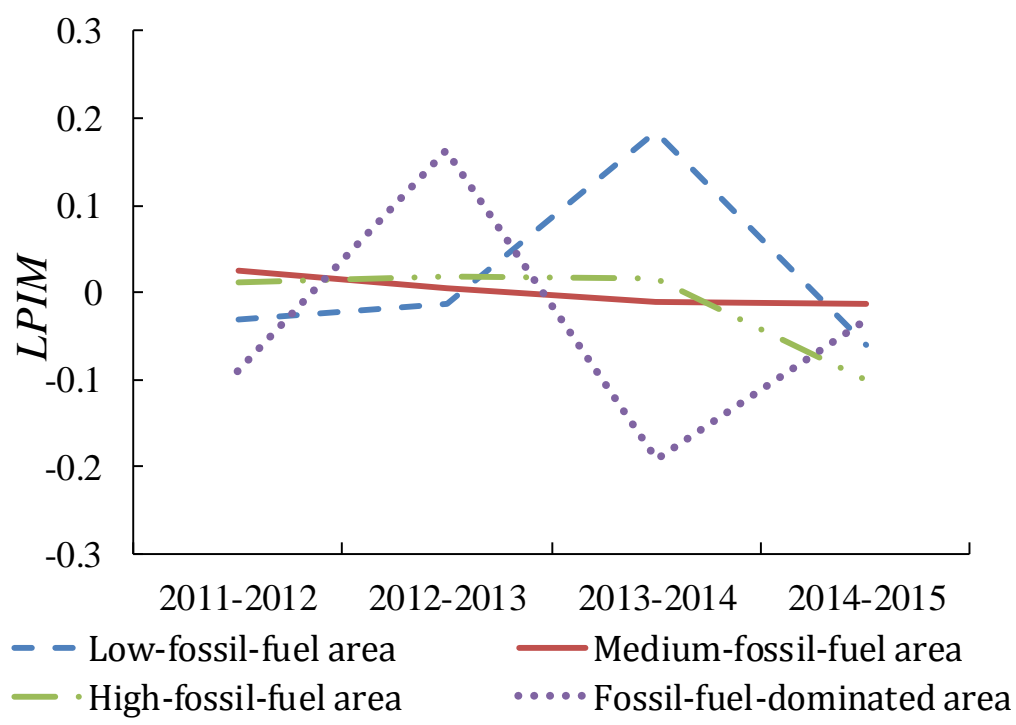

Fig. 7 Productivity change between groups for four areas during 2011-2015

Table 5 The results of $T$-test for $L P I M$

\begin{tabular}{lll}
\hline Group & $t$ & Sig. \\
\hline Low-fossil-fuel area & 0.356 & 0.746 \\
Medium-fossil-fuel area & 0.192 & 0.860 \\
High-fossil-fuel area & -0.457 & 0.679 \\
Fossil-fuel-dominated area & -0.507 & 0.647 \\
\hline \multicolumn{2}{l}{ Note: Significant level at 5\%. }
\end{tabular}

To provide a clear picture, Table 6 presents the average LPIM and its decomposition for each group in the $12^{\text {th }}$ FYP. The average LPIM is calculated by the arithmetic average value of each scenario during the period of 2011-2015. Firstly, in terms of average $T E C$, the low-fossil-fuel area has the highest increase of 0.0022 followed by the medium-fossil-fuel area with 0.0004 . While the high-fossil-fuel area and fossil-fuel-dominated area have a decrease in technical efficiency by -0.0095 and -0.0283 , respectively. This indicates that the low-fossil-fuel area shows the best performance on the catch-up effect.

Secondly, with respect to the average $B P C$, the medium-fossil-fuel area, high-fossil-fuel area and fossil-fuel-dominated area present the similar technical progress of $0.0195,0.0203$ and 0.0141 , whereas the low-fossil-fuel area faces a 0.0082 technical progress. One of the most vital reasons may be due to the fact that the regions based on thermal power for electricity generation need a relatively 
advanced technology than the regions that have a relatively high share of renewable energy consumption in total energy consumption.

Finally, the average $T G C$ shows an increase in low-fossil-fuel area (0.0206), wheaeas it shows a reduction in medium-fossil-fuel area (-0.0332), high-fossil-fuel area $(-0.0549)$ and fossil-fuel-dominated area (-0.0441). This result indicates that an enlarger gap between the ITF of last three areas and the $M T F$. Since the $T G C$ measures the change in technological leadership, it can be interpreted that these three areas show no technological leadership progress.

Regarding the LPIM reported in Table 7, the most obvious productivity growth occurs in the low-fossil-fuel area, and this growth is driven by the promotion of technical efficiency and technological leadership. On the contrary, the medium-fossil-fuel area, high-fossil-fuel area and fossil-fossil-dominated area show productivity decline. Technological leadership regress is the primary driving force for the decline in medium-fossil-fuel area, whereas technical efficiency deterioration and technological leadership regress are both the primary driving forces leading to the drop for high-fossil-fuel area and fossil-fossil-dominated area. An interesting observation is that, the scores on LPIM decline associated with the increasing proportion of fossil fuel consumption in total energy consumption for electricity generation. Hence, it can be suggested that increasing the share of clean energy in electricity generation may help to accelerate the productivity progress in China's power industry.

Table 6 LPIM and its decomposition for each group in the period of 2011-2015

\begin{tabular}{llllll}
\hline Group & Region & LPIM & TEC & BPC & TGC \\
\hline \multirow{7}{*}{ Low-fossil-fuel area } & Hubei & -0.0560 & 0 & -0.0579 & 0.0019 \\
& Hunan & -0.0480 & 0 & -0.2009 & 0.1529 \\
& Guangxi & -0.0210 & 0 & 0.0755 & -0.0965 \\
& Sichuan & 0.0895 & 0 & 0.0691 & 0.0203 \\
& Yunnan & 0.1613 & 0.0156 & 0.1384 & 0.0073 \\
& Gansu & -0.0126 & 0 & -0.0813 & 0.0687 \\
& Qinghai & -0.0101 & 0 & 0 & -0.0101 \\
& Average & $\mathbf{0 . 0 1 4 7}$ & $\mathbf{0 . 0 0 2 2}$ & $\mathbf{- 0 . 0 0 8 2}$ & $\mathbf{0 . 0 2 0 6}$ \\
\hline Medium-fossil-fuel area & Jilin & 0.0016 & 0.0206 & 0.0418 & -0.0609
\end{tabular}




\begin{tabular}{|c|c|c|c|c|c|}
\hline & Zhejiang & -0.0402 & 0 & 0 & -0.0402 \\
\hline & Fujian & -0.0733 & 0 & 0 & -0.0733 \\
\hline & Jiangxi & -0.0444 & 0 & -0.0393 & -0.0051 \\
\hline & Guangdong & 0.0586 & 0 & 0 & 0.0586 \\
\hline & Chongqing & -0.0830 & 0 & 0 & -0.0830 \\
\hline & Guizhou & -0.0056 & -0.0267 & 0.0607 & -0.0396 \\
\hline & Xinjiang & 0.0797 & 0.0091 & 0.0926 & -0.0220 \\
\hline & Average & -0.0133 & 0.0004 & 0.0195 & -0.0332 \\
\hline \multirow{8}{*}{ High-fossil-fuel area } & Hebei & -0.0755 & 0 & -0.0281 & -0.0474 \\
\hline & Inner Mongolia & 0.0428 & 0 & 0.0168 & 0.0260 \\
\hline & Liaoning & -0.0047 & 0 & 0.0566 & -0.0614 \\
\hline & Heilongjiang & -0.0155 & -0.0668 & 0.0806 & -0.0294 \\
\hline & Hainan & -0.1017 & 0 & 0 & -0.1017 \\
\hline & Shaanxi & -0.1193 & 0 & 0.0164 & -0.1357 \\
\hline & Ningxia & -0.0346 & 0 & 0 & -0.0346 \\
\hline & Average & -0.0441 & -0.0095 & 0.0203 & -0.0549 \\
\hline \multirow{9}{*}{ Fossil-fuel-dominated area } & Beijing & 0.0960 & 0 & 0 & 0.0960 \\
\hline & Tianjin & -0.0309 & 0 & -0.0197 & -0.0113 \\
\hline & Shanxi & -0.2041 & -0.1283 & 0.0099 & -0.0857 \\
\hline & Shanghai & -0.2417 & 0 & -0.0605 & -0.1812 \\
\hline & Jiangsu & 0.0064 & 0 & 0.0059 & 0.0006 \\
\hline & Anhui & -0.1500 & -0.1077 & 0.0435 & -0.0858 \\
\hline & Shandong & 0.2054 & 0.0291 & 0.1021 & 0.0741 \\
\hline & Henan & -0.1480 & -0.0199 & 0.0316 & -0.1598 \\
\hline & Average & -0.0584 & -0.0283 & 0.0141 & -0.0441 \\
\hline
\end{tabular}

\section{Discussions}

Overall, the feasibility studies show that even if all electricity generation units adopt their best practice, the $\mathrm{CO}_{2}$ emissions intensity reduction target in $13^{\text {th }}$ FYP period is infeasible in the short term and in the medium term. Based on the analyses, several findings can be obtained as follows. The estimation results indicate that the maximum reduction potential of almost all regions would still be below the $13^{\text {th }}$ FYP target if only improving the technical efficiency and upgrading the technology on electricity generation and carbon abatement in a short or medium term. A large scale of efficiency improvement is only achievable in the long term associated with the technological transfer among areas, and the effective adjustment of generation fuel mix for electricity generation and carbon abatement. Moreover, the largest reduction potentials on $\mathrm{CO}_{2}$ emissions intensity are different among 
regions. Therefore, the targets for $\mathrm{CO}_{2}$ emissions reduction should be variously assigned across regions.

To inform designing better emission control targets for China's power industry across regions in the future, the productivity change and its decomposition are also analyzed. The estimation shows that, i) The low-fossil-fuel area and the fossil-fuel-dominated area have smaller emission reduction potential than the other areas during our study period. One possible reason is that the low-fossil-fuel area has a relatively high share of renewable electricity generation, and there is no $\mathrm{CO}_{2}$ emissions from the using of renewable energy such as solar power, wind power and hydropower. Therefore, when generating the same level of electricity, the low-fossil-fuel area has lower $\mathrm{CO}_{2}$ emissions than the other areas. In addition, the fossil-fuel-dominated area, which relies on thermal power in electricity generation, has a better technology with a relatively low fuel consumption rate for electricity generation.

ii) The LPIM of all groups shows almost no growth in the long term because there is no siginificant increase in technical efficiency, upgrade in technology and technological transfer on electricity generation and carbon abatement. This suggests weakness in controlling carbon emissions and further actions, such as inter-regional technology transfer, more renewable energy introduction and limiting the operation of the backward capacity, are needed.

iii) With respect to the decomposition of the LPIM, the low-fossil-fuel area has the best performance on the catch-up effect, but presents the lowest technical progress, whereas only this area shows technological leadership progress. Table 7 summaries the situation of LPIM and its decomposition for each group. On the one hand, the low-fossil-fuel area experience the productivity growth, and its growth is driven by the technical efficiency improvement and technological leadership progress. On the other hand, the medium-fossil-fuel area, high-fossil-fuel area and the fossil-fuel-dominated area experience productivity reductions. Specifically, the technological 
leadership regress causes the LPIM decline of the medium-fossil-fuel area, while the technical efficiency deterioration and the technological leadership regress both lead to this drop for high-fossil-fuel area and fossil-fuel-dominated area. 
Table 7 Summaries on LPIM and its decomposition for each group

\begin{tabular}{|c|c|c|c|c|c|c|}
\hline & $\begin{array}{l}\text { Definition: share of fossil } \\
\text { fuel consumption in total } \\
\text { energy consumption for } \\
\text { electricity generation }\end{array}$ & $\begin{array}{c}\text { Technology } \\
\text { gap }\end{array}$ & $\begin{array}{c}\text { Productivity } \\
\text { change }\end{array}$ & $\begin{array}{l}\text { Technical } \\
\text { efficiency change }\end{array}$ & $\begin{array}{l}\text { Technical } \\
\text { change }\end{array}$ & $\begin{array}{l}\text { Technological } \\
\text { leadership change }\end{array}$ \\
\hline Low-fossil-fuel area & $0-65 \%$ & Low & Growth (best) & Improvement (best) & Regress (worst) & Progress (best) \\
\hline Medium-fossil-fuel area & $65 \%-85 \%$ & High & Reduction & Improvement & Progress & Regress \\
\hline High-fossil-fuel area & $85 \%-94 \%$ & High & Reduction & Deterioration & Progress & Regress \\
\hline Fossil-fuel-dominated area & $94 \%-100 \%$ & Low & Reduction & Deterioration & Progress & Regress \\
\hline
\end{tabular}




\section{Conclusion}

Electricity generation, which accounts for a relatively large share in energy consumption and $\mathrm{CO}_{2}$ emissions, is one of the most important industrial sectors in China's effort to control carbon emission. This article discusses whether the proposed nationwide and provincial $\mathrm{CO}_{2}$ emissions intensity reduction target of the $13^{\text {th }}$ FYP would be achievable for the existing generating units through scenario analysis. It also tries to inform future policy improvement by revealing the driving forces of carbon productivity change.

To capture the feasible reduction in $\mathrm{CO}_{2}$ emissions intensity, this paper estimates the maximizing reduction potential in $\mathrm{CO}_{2}$ emissions intensity by increasing the electricity generation and decreasing the related $\mathrm{CO}_{2}$ emissions under four illustrative scenarios. More specifically, it tries to examine which $\mathrm{CO}_{2}$ emissions intensity would be feasible if all the electricity-generating units adopt their best practice. In other words, this paper conducts the scenario analysis to identify how much the current $\mathrm{CO}_{2}$ emissions intensity of the power industry sector would be reduced if the plants operated at various technological frontiers.

The study find that the nationwide $18 \% \mathrm{CO}_{2}$ reduction target is not feasible through improving technical efficiency or upgrading technology on electricity generation and carbon abatement in a short or medium term. The inter-regional technology transfer and the effective adjustment of generation fuel mix for electricity generation are needed to increase the efficiency in the uses of energy and the control of carbon emissions. For most provinces, the $18 \%$ reduction target is not difficult to achieve. However, there is significant inter-regional heterogeneity in technologies and thus productivity. It is also found that there is no much potential for all areas to improve overall 
productivity in a five-year period. By group, only low-fossil-fuel area has little overall productivity growth (0.0147) driven by technical efficiency improvement and technological leadership progress, whereas medium-fossil-fuel area experiences overall productivity decline mainly driven by technological leadership regress, and high-fossil-fuel area and fossil-fuel-dominated area also experience overall productivity decline driven by both technical efficiency deterioration and technological leadership regress.

The present offers the following policy implication. First, since the largest reduction percentages on $\mathrm{CO}_{2}$ emissions intensity are various among regions, the regulations and policies for $\mathrm{CO}_{2}$ emissions intensity reduction should be more differentiated across different regions. Second, considering the limited overall productivity improvement potential in the short and medium term, and the significant regional heterogeneity, inter-region technology transfer, introducing more renewable energy and limiting the operation of the backward capacity could promote emission control as well as productivity growth. This is particular true within the thermal power generation category where advanced technologies could be transferred from one region to another. Third, consider high renewable energy share lead to high productivity growth, promoting clean energy consumption in electricity generation may help to improve the carbon productivity. This suggestion is actually in line with the development plan of China's power industry for INDC, in which to increase the share of non-fossil fuels in the total primary energy supply to 20 percent by 2030 is targeted. Lastly, the emerging national emission trading scheme will make policy formulation for heterogeneous regions much easier. However, regional specific emission targets under a national ETS are still necessary to prevent those regions with limited abatement potential being overburden to buy carbon credits. 


\section{Acknowledgment}

We gratefully acknowledge the financial support from the National Natural Science Foundation of China (Grant Nos. 71471018, 71521002 and 71761137001), the Social Science Foundation of Beijing (Grant No. 16JDGLB013), the Joint Development Program of Beijing Municipal Commission of Education, the Fok Ying Tung Education Foundation (161076), the National Key R\&D Program (Grant No. 2016YFA0602603), the International Clean Energy Talent Program of Chinese Scholarship Council, and the Key Technology Partnership (KTP) Visiting Fellow Program at UTS and BIT.

\section{References}

Adler, N., Voltab, N., 2016. Accounting for externalities and disposability: A directional economic environmental distance function. Eur. J. Oper. Res. 250, 314-327.

Azad, M.A.K., Munisamy, S., Masum, A.K.M., Saona, P., Wanke, P.F., 2017. Bank efficiency in Malaysia: a use of malmquist meta-frontier analysis. Eurasian Bus. Rev. 7, 287-311.

Barros, C.P., Wanke, P., 2017. Efficiency in Angolan thermal power plants: Evidence from cost structure and pollutant emissions. Energ. 130, 129-143.

Barros, C.P., Wanke, P., 2017. Technology Gaps and Capacity Issues in African Insurance Companies: Selected Country Evidence. J. Int. Dev. 29(1), 117-133. 
Barros, C.P., Wanke, P., Dumbo, S., Manso, J.P., 2017. Efficiency in angolan hydro-electric power station: A two-stage virtual frontier dynamic DEA and simplex regression approach. Renew. Sust. Energ. Rev. 78, 588-596.

Battese, G.E., Rao, D.S.P., 2002. Technology gap, efficiency, and a stochastic metafrontier function. Int. J. Bus. Econ. 1(2), 87-93.

Battese, G.E., Rao, D.S.P., O’Donnell, C.J., 2004. A metafrontier production function for estimation of technical efficiencies and technology gaps for firms operating under different technologies. J. Prod. Anal. 21(1), 91-103.

Bjorn, L., 2016. Impact of Current Climate Proposals. Glob. Policy. 7(1), 109-118.

Chambers, R.G., Chung, Y., Färe, R., 1996a. Benefit and Distance Functions. J. Econ. Theory. 70, 407-419.

Chen, C.-M., Delmas, M.A., 2012. Measuring Eco-Inefficiency: A New Frontier Approach. Oper. Res. 60(5), 1064-1079.

Chen, Z., Wanke, P., Antunes, J.J.M., Zhang, N., 2017. Chinese airline efficiency under CO2 emissions and flight delays: A stochastic network DEA model. Energ. Econ. 68, 89-108,

Chen, J.D., Cheng, S.L., Nikic, V., Song, M.L., 2018. Quo Vadis? Major Players in Global Coal Consumption and Emissions Reduction. Transf. Bus. Econ. 17(1), 112-132.

Chung, Y., Färe, R., Grosskopf, S., 1997. Productivity and undesirable outputs: a directional distance function approach. J. Environ. Manage. 51, 229-240.

Díaz-Villavicencio, G., Didonet, S.R., Dodd, A., 2017. Influencing factors of eco-efficient urban waste management: Evidence from Spanish municipalities. J. Clean. Prod. 164, 1486-1496. 
Du, K., Huang, L., Yu, K., 2014. Sources of the potential CO2 emission reduction in China: A nonparametric metafrontier approach. Appl. Energ. 115, 491-501.

Fallahfini, S., Triantis, K.P., La Garza, J.M., Seaver, W. 2012. Measuring the efficiency of highway maintenance contracting strategies: A bootstrapped non-parametric meta-frontier approach. Eur. J. Oper. Res. 219(1), 134-145.

Färe, R., Grosskopf, S., 2004. New Directions: Efficiency and Productivity. Boston: Kluwer Academic Publishers.

Färe, R., Grosskopf, S., Pasurka, C.A., Weber, W., 2012. Substitutability among undesirable outputs. Appl. Econ. 44, 39-47.

Färe, R., Grosskopf, S., Wittaker, G., 2013. Directional Output Distance Functions: Endogenous Constraints Based on Exogenous Normalization Constraints. J. Prod. Anal. 40, 267-269.

Feng, C., Wang, M., Zhang, Y., Liu, G.-C., 2018. Decomposition of energy efficiency and energy-saving potential in China: A three-hierarchy meta-frontier approach. J. Clean. Prod. 176, 1054-1064.

Fetanat, A., Shafipour, G., 2017. A hybrid method of LMDI, symmetrical components, and SFA to estimate the distribution of energy-saving potential with consideration of unbalanced components in decomposition analysis, Energ. Effic. 10(4), 1041-1059.

Fukuyama, H., Weber, W.L., 2009. A directional slacks-based measure of technical inefficiency. Socio-Econ. Plan. Sci. 43, 274-287.

Halkos, G. E., Stern, D. I., Tzeremes, N. G., 2016. Population, economic growth and regional environmental inefficiency: evidence from US states. J. Clean. Prod. 112, 4288-4295. 
Hampf, B., Krüger, J.J., 2014. Optimal Directions for Directional Distance Functions: An

Exploration of Potential Reductions of Greenhouse Gases. Am. J. Agr. Econ. 97, 920-938.

Hampf, B., Rødseth, K.L., 2015. Carbon dioxide emission standards for U.S. power plants: An efficiency analysis perspective. Energ. Econ. 50, 140-153.

Hančlová, J. Melecký, L. 2016. Application of the Nonparametric DEA Meta-frontier Approach with Undesirable Outputs in the Case of EU Regions. Bus. Syst. Res. J. 7(2), 65-77.

Hayami, Y., 1969. Sources of agricultural productivity gap among selected countries. Am. J. Agric. Econ. 51(3), 564-575.

Heshmati, A., Lee, S., Hwang, W., 2012. Performance analysis of power plants under heterogeneous technologies with meta frontier framework. Int. J. Econ. Manag. Eng. 2(1), 5-14.

IEA, 2011. $\mathrm{CO}_{2}$ Emissions from fuel combustion highlights. http://www.iea.org/media/statistics/co2highlights.pdf. (accessed 01 June 2015).

IPCC, 2013. Climate Change 2013: The Physical Science Basis, Cambridge University Press, Cambridge.

Lee, C., Lee D., Hwang, J., 2015. Platform openness and the productivity of content providers: A meta-frontier analysis. Telecommun. Policy. 39(7), 553-562.

Lin, B., Zhao, H., 2016. Technology gap and regional energy efficiency in China's textile industry: A non-parametric meta-frontier approach. J. Clean. Prod. 137, 21-28.

Makni, R., Benouda, O., Delhoumi, E. 2015. Large scale analysis of Islamic equity funds using a meta-frontier approach with data envelopment analysis. Res. Int. Bus. Financ. 324-337.

Moreira, V.H. Bravo-Ureta, B.E., 2010. Technical efficiency and metatechnology ratios for dairy 
farms in three southern cone countries: a stochastic meta-frontier model. J. Prod. Anal. 33(1), $33-45$.

Munisamy, S., Arabi, B., 2015. Eco-efficiency change in power plants: using a slacks-based measure for the meta-frontier Malmquist-Luenberger productivity index. J. Clean. Prod. 105, 218-232.

NDRC, 2016. National Development and Reform Commission: The electric power development planning "in 13th Five-Year" (2016-2020). http://www.gov.cn/xinwen/2016-12/22/5151549/files/696e98c57ecd49c289968ae2d77ed583.pdf. (accessed 10 June, 2018)

Oh, D.-h., 2010. A metafrontier approach for measuring an environmentally sensitive productivity growth index. Energ. Econ. 32(1), 146-157.

O'Donnell, C., Rao, D., Battese, G., 2008. Metafrontier frameworks for the study of firmlevel efficiencies and technology ratios. Empir. Econ. 34 (2), 231-255.

Paltsev, S., Morris, J., Cai, Y.S., Karplus, V., Jacoby, H., 2012. The role of China in mitigating climate change. Energ. Econ. 34(3), 444-450.

Park, P. J., Tahara, K., 2008. Quantifying producer and consumer-based eco-efficiencies for the identification of key ecodesign issues. J. Clean. Prod. 16(1), 95-104.

Picazo-Tadeo, A.J., Beltrán-Esteve, M., Gómez-Limón, J.A., 2012. Assessing eco-efficiency with directional distance functions. Eur. J. Oper. Res. 220, 798-80.

Picazo-Tadeo, A.J., Prior, D., 2009. Environmental Externalities and Efficiency Measurement. J. Environ. Manage. 90, 3332-3339.

Qi, S, Li, Y., 2017. Threshold effects of renewable energy consumption on economic growth under 
energy transformation. Chinese J. Popul. Resour. Environ. 15(4): 312-321.

SCC, 2007. State Council of the People's Republic of China: Comprehensive Work Plan for Energy Conservation and Emissions Reduction. http://www.gov.cn/zwgk/2007-06/03/content_634545.htm. (accessed 15 November 2016).

SCC, 2011a. State Council of the People's Republic of China: comprehensive work plan for energy conservation and emissions reduction in the $12^{\text {th }}$ five year plan period. http://www.gov.cn/zwgk/2011-09/07/content_1941731.htm. (accessed 15 November 2016).

SCC, 2011b. State Council of the People's Republic of China: work plan for greenhouse emissions control in the $12^{\text {th }}$ five year plan period.

http://www.gov.cn/zhengce/content/2012-01/13/content_1294.htm. (accessed 15 November 2016).

SCC, 2016. State Council of the People's Republic of China: work plan for greenhouse emissions control in the $13^{\text {th }}$ five year plan period. http://www.gov.cn/zhengce/content/2016-11/04/content_5128619.htm. (accessed 15 November 2016).

Shephard, R.W., 1970. Theory of Cost and Production Functions. Princeton University Press, Princeton, NJ.

Sueyoshi, T., Li, A., Gao, Y., 2018. Sector sustainability on fossil fuel power plants across Chinese provinces: Methodological comparison among radial, non-radial and intermediate approaches under group heterogeneity. J. Clean. Prod. 187, 819-829. 
Vardanyan, M., Noh, D.W., 2006. Approximating pollution abatement costs via alternative specifications of a multi-output production technology: a case of US electric utility industry. J. Environ. Manage. 80, 177-190.

Wanke, P.F., Barros, C.P., 2016 Efficiency drivers in Brazilian insurance: A two-stage DEA meta frontier-data mining approach. Econ. Model. 53, 8-22.

Wanke, P.F., Hadi-Vencheh, A., Forghani, A., 2017. A DDF based model for efficiency evaluation in two-stage DEA. Optim Lett. 1-16.

Wang, K., Wei, Y.M., Zhang, X., 2013. Energy and emissions efficiency patterns of Chinese regions: a multi-directional efficiency analysis. Appl. Energ. 104, 105-116.

Wang, K., Xian, Y.J., Wei, Y.M., Huang Z., 2016a. Sources of carbon productivity change: A decomposition and disaggregation analysis based on global Luenberger productivity indicator and endogenous directional distance function. Ecol. Indic. 66, 545-555.

Wang, K., Lee, C.Y., Zhang, J., Wei, Y.M., 2016b. Operational performance management of the power industry: A distinguishing analysis between effectiveness and efficiency. Ann. Oper. Res. doi: 10.1007/s10479-016-2189-1.

Wang, K., Wei, Y.M., 2016c. Sources of energy productivity change in China during 1997-2012: A decomposition analysis based on the Luenberger productivity indicator. Energ. Econ. 54, 50-59.

Wang, K., Xian, Y., Zhang, J., Li, Y., Che, L., 2016d. Potential carbon emission abatement cost recovery from carbon emission trading in China: An estimation of industry sector. J. Model. Manage. 11(3), 842-854. 
Wang, K., Xian, Y., Lee, C.Y., Wei, Y.M., Huang, Z., 2017. On selecting directions for directional distance functions in a non-parametric framework: A review. Ann. Oper. Res. doi: 10.1007/s10479-017-2423-5.

Wang, K., Wei, Y.M., Huang, Z., 2018a. Environmental efficiency and abatement efficiency measurements of China's thermal power industry: A data envelopment analysis based materials balance approach. Eur. J. Oper. Res. 269(1), 35-50.

Wang, K., Mi, Z., Wei, Y.M., 2018b. Will pollution taxes improve joint ecological and economic efficiency of thermal power industry in China? A DEA-based materials balance approach. J. Ind. Ecol. doi: 10.1111/jiec.12740. 